Florida International University FIU Digital Commons

FIU Electronic Theses and Dissertations

University Graduate School

$11-12-2015$

\title{
Cellular Events Under Flow States Pertinent to Heart Valve Function
}

Glenda L. Castellanos

Florida International University, gcast117@fiu.edu

DOI: $10.25148 /$ etd.FIDC000184

Follow this and additional works at: https://digitalcommons.fiu.edu/etd

Part of the Molecular, Cellular, and Tissue Engineering Commons

\section{Recommended Citation}

Castellanos, Glenda L., "Cellular Events Under Flow States Pertinent to Heart Valve Function" (2015). FIU Electronic Theses and Dissertations. 2285.

https://digitalcommons.fiu.edu/etd/2285

This work is brought to you for free and open access by the University Graduate School at FIU Digital Commons. It has been accepted for inclusion in FIU Electronic Theses and Dissertations by an authorized administrator of FIU Digital Commons. For more information, please contact dcc@fiu.edu. 


\title{
FLORIDA INTERNATIONAL UNIVERSITY
}

\author{
Miami, Florida
}

\section{CELLULAR EVENTS UNDER FLOW STATES PERTINENT TO HEART VALVE FUNCTION}

\author{
A thesis submitted in partial fulfillment of the \\ requirements for the degree of \\ MASTER OF SCIENCE \\ in \\ BIOMEDICAL ENGINEERING \\ by
}

Glenda Castellanos

2015 
To: Interim Dean Ranu Jung

College of Engineering and Computing

This thesis, written by Glenda Castellanos, and entitled Cellular Events under Flow States Pertinent to Heart Valve Function, having been approved in respect to style and intellectual content, is referred to you for judgment.

We have read this thesis and recommend that it be approved.

Jessica Ramella-Roman

Wei-Chiang Lin

Date of Defense: November 12, 2015

Sharan Ramaswamy, Major Professor

The thesis of Glenda Castellanos is approved.

Interim Dean Ranu Jung

College of Engineering and Computing

Dean Lakshmi N. Reddi

University Graduate School

Florida International University, 2015 
(C) Copyright 2015 by Glenda Castellanos

All rights reserved. 


\section{DEDICATION}

I would like to dedicate this thesis to my family, whom have been always very supportive throughout my studies. Words will always fall short when trying to express my gratitude towards them. Without their patience and great love this wouldn’t have been possible. 


\section{ACKNOWLEDGMENTS}

I would like to express my most sincere gratitude to everyone who has contributed professionally and personally to this thesis. In particular, I wish to thank Dr.Ramaswamy for providing me the guidance and kind words of encouragement throughout my studies. It has been a pleasure and honor working under your wing. My friends, for making this journey a pleasant one with good humor and priceless friendship. Arash, for your support, understanding, and love throughout the times of stress and happiness. UGS for providing me with funding in order to fulfill this degree, and the BME department for making the workplace a memorable one. 


\author{
ABSTRACT OF THE THESIS \\ CELLULAR EVENTS UNDER FLOW STATES PERTINENT TO HEART \\ VALVE FUNCTION \\ by \\ Glenda Castellanos
}

Florida International University, 2015

Miami, Florida

\title{
Professor Sharan Ramaswamy, Major Professor
}

Heart valve disease (HVD) or a damaged valve can severely compromise the heart's ability to pump efficiently. Balloon valvuloplasty is preferred on neonates with aortic valve stenosis. Even though this procedure decreases the gradient pressure across the aortic valve, restenosis is observed soon after balloon intervention. Tissue engineering heart valves (TEHV), using bone marrow stem cells (BMSCs) and biodegradable scaffolds, have been investigated as an alternative to current non-viable prosthesis. By observing the changes in hemodynamics following balloon aortic valvuloplasty, we could uncover a potential cause for rapid restenosis after balloon intervention. Subsequently, a tissue engineering treatment strategy based on BMSC mechanobiology could be defined. Understanding and identifying the mechanisms by which cytoskeletal changes may lead to cellular differentiation of a valvular phenotype is a first critical step in enhancing the promotion of a robust valvular phenotype from BMSCs. 


\section{TABLE OF CONTENT}

CHAPTER

PAGE

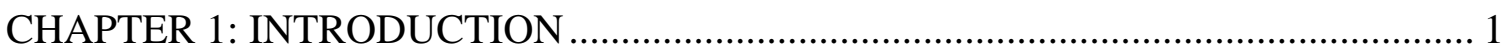

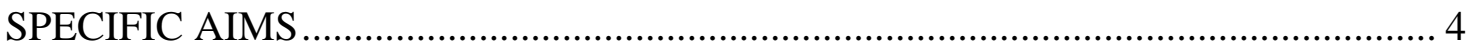

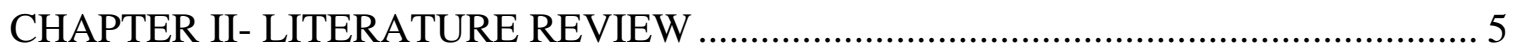

Composition of the Aortic Heart Valve and Function ................................................... 5

Valvular Endothelial Cells (VECs) ........................................................................ 6

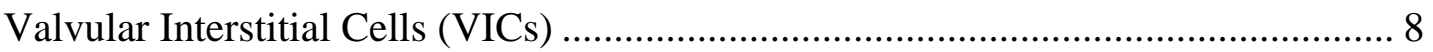

Aortic Heart Valve Hemodynamics ........................................................................ 9

Heart Valve Disease ................................................................................................. 10

Heart Valve Tissue Engineering .................................................................................... 12

CHAPTER III: STEM CELL STRUCTURAL ADAPTATION TO FLOW:

IMPLICATIONS FOR VALVULOGENESIS............................................................. 15

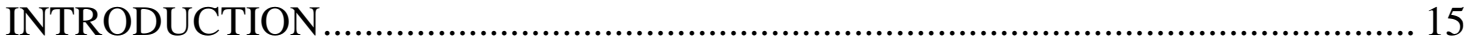

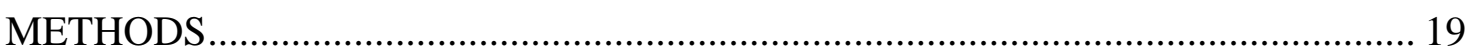

Culture and Expansion of BMSCs ................................................................... 19

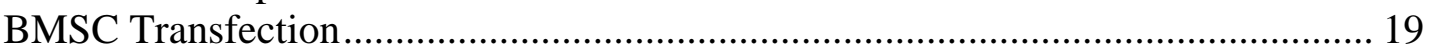

Transfection Efficiency ………………………………………………………. 19

Fluid-Induced Mechanobiology Experiments ......................................................... 20

Cell Structure Quantification............................................................................... 20

Statistical Analysis .......................................................................................... 21

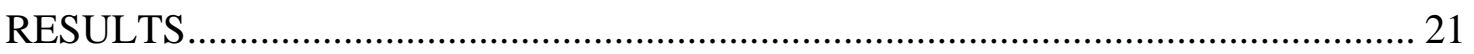

Transfection Efficiency .................................................................................. 21

Number of Actin filaments ............................................................................... 22

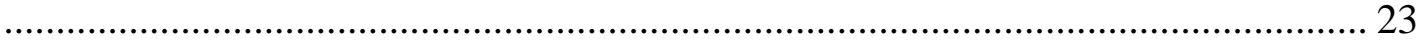

F-actin filament length ..................................................................................... 24

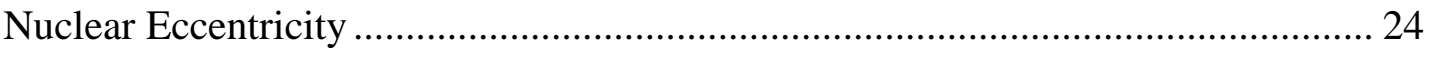

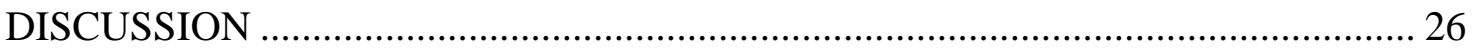

CHAPTER IV: OBSERVING CHANGES IN HEMODYNAMICS OF A HEALTHY HEART VALVE AND A TREATED HEART VALVE USING A

COMPUTATIONAL MODEL ………………………........................................ 30

INTRODUCTION

METHODS.............................................................................................. 31

Isolation of porcine valvular endothelial cells (VECs) ............................................. 31

Immunostaining VECs ........................................................................................... 31 


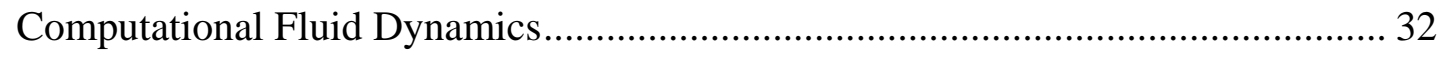

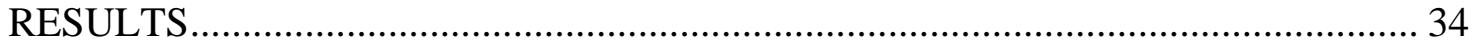

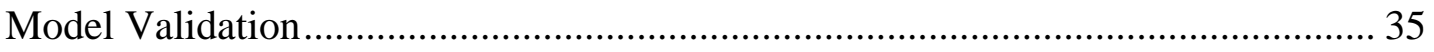

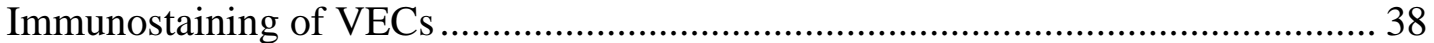

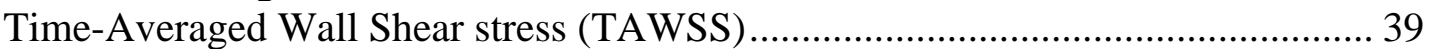

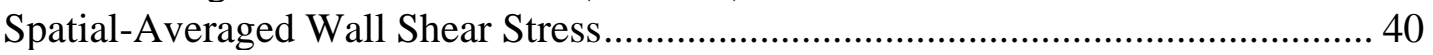

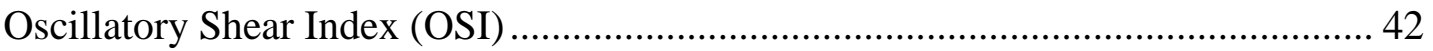

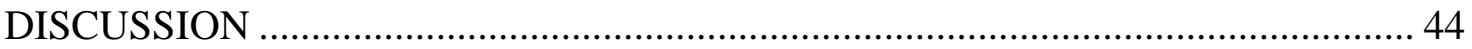

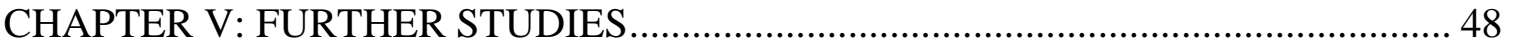

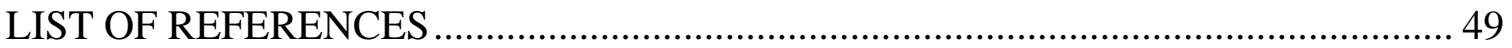




\section{LIST OF FIGURES}

FIGURE

PAGE

Figure 1. Heart valve composition showing fibrosa, spongiosa, and ventricularis.

(Wirrig, 2013)

Figure 2. EMT process during heart valve formation. Endothelial cells going through

EMT and migrating into the interstitial space (cardiac jelly) (Bischoff, 2007)............... 8

Figure 3. The composition of a normal heart valve and a stenotic heart valve (USC, 2012).

Figure 4. Transfected BMSCs with actin GFP were assessed two days after electroporation using flow cytometry; $77.43 \%$ of the cells were shown to express high GFP intensity as seen in the first quadrant.

Figure 5. Transfected BMSCs with actin GFP assessed two days after transfection were incubated in propidium iodide (PI) solution to evaluate cellular viability; $50.07 \%$ of cells were efficiently transfected and viable after electroporation, as seen in 22

Figure 6.The effect of BMSC when exposed to OSS, SS, and No Flow (static) conditions on the number of actin filaments ( $n=8$ wells/group).

Figure 7. OSS, SS, and No Flow (static) conditions on average BMSC actin filament length ( $\mathrm{n}=8$ wells/group).

Figure 8. Nuclear eccentricity (circularity) in BMSCs while being exposed to OSS, $\mathrm{SS}$, and No Flow (static) conditions ( $\mathrm{n}=8$ wells/group)

Figure 9. Transfected BMSCs imaged at No Flow (static) conditions at 0 hours and at 48hours. Yellow arrows point to the actin filaments and red arrows show the nucleus... 25

Figure 10. Transfected cells showing filament orientation at 0 and 48 hours. SS group. 25

Figure 11. Transfected cells showing filament orientation under OSS. 25

Figure 12. Echocardiography flow profiles from normal patient obtained from JDCH... 32 
Figure 13. Echocardiography flow profiles from patient after balloon valvuloplasty

obtained from JDCH.

Figure 14. Velocity profile from a normal fed to the inlet in the simulation (Ansys CFD).

Figure 15. Velocity profile from a patient after balloon valvuloplasty fed to the inlet in the simulation (Ansys CFD)

Figure 16. Pressure profile from a normal patient fed to the outlet in the simulation (Ansys CFD). 34

Figure 17. Pressure profile from a patient after balloon valvuloplasty fed to the outlet in the simulation (Ansys CFD). 35

Figure 18. Transvavlular pressure gradient validation on the post-balloon valvuloplasty model 36

Figure 19. Inlet pressure waveform validation from treated heart valve. 36

Figure 20. Transvalvular pressure gradient validation on the normal heart valve model. 37

Figure 21 Inlet pressure validation from a healthy heart valve. 37

Figure 22. Isolated VECs stained positive for CD31 (Left). VECs stained negative for

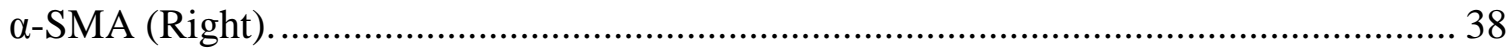

Figure 23. Time average wall shear stress on a normal patient......................................... 39

Figure 24. Time average wall shear stress on patient after treatment............................... 40

Figure 25. Spatially-averaged wall shear stress from the normal patient .......................... 41

Figure 26. Spatially-averaged wall shear stress after balloon valvuloplasty.................... 41

Figure 27. OSI fibrosa side of the healthy heart valve ..................................................... 42

Figure 28.OSI ventricularis side of the healthy heart valve............................................... 43 
Figure 29. OSI fibrosa side of a heart valve that underwent treatment.

Figure 30. OSI ventricularis side of the heart valve that underwent treatment. .............. 44 


\section{ABBREVIATIONS AND ACRONYMS}

\begin{tabular}{|c|c|}
\hline AVS & Aortic valve stenosis \\
\hline BMSC & Bone marrow stem cell \\
\hline EMT & Endothelial-mesenchymal transformation \\
\hline GFP & Green fluorescent protein \\
\hline OSI & Oscillatory shear index \\
\hline OSS & Oscillatory shear stress \\
\hline PGA & Polyglycolic acid \\
\hline PI & Propidium iodide \\
\hline PLLA & Poly-L lactic acid \\
\hline SS & Steady state \\
\hline TEHV & Tissue engineered heart valve \\
\hline VEC & Valvular endothelial cell \\
\hline VIC & Valvular interstitial cell \\
\hline WSS & Wall shear stress \\
\hline
\end{tabular}




\section{CHAPTER 1: INTRODUCTION}

Valvular heart disease is a serious cardiovascular complication. Approximately 275000 people in the United States undergo heart valve replacement every year; 5000 are children ${ }^{1}$. Heart valves perform a critical role in maintaining unidirectional blood flow. The tissue and cells that constitute the leaflets must have unique characteristics that allow them to open and close properly, as well as remodel as needed ${ }^{2}$. The leaflets also experience complex mechanical stresses which their composition and structure allows them to endure ${ }^{3}$. They are comprised of three different layers, which include the fibrosa (facing the artery), ventricularis (facing the ventricle), and the spongiosa, which is located between the fibrosa and the ventricularis ${ }^{4}$. Similar to blood vessels, the surface of the heart valves are lined with endothelial cells, which have been known to have the ability to sense and respond to different mechanical and hemodynamic environments, and rapidly change their behavior ${ }^{2,3}$. However, in vitro studies have suggested that vascular and valvular endothelial cells are distinct in their response to hemodynamics ${ }^{2}$.

Congenital heart defects are the most common birth defect, with about $1 \%$ of the population being affected by them ${ }^{4}$. Around $24.5 \%$ of neonatal mortality is due to congenital heart defects ${ }^{5}$, one of the most severe being critical aortic valve stenosis (AVS), a life-threatening condition with high morbidity despite early intervention. Open surgical valvotomy and a less invasive procedure, transcatheter balloon valvuloplasty of the aortic valve, are two of the most used and recognized procedures done TO neonates with AVS. Balloon valvuloplasty has been shown to reduce the pressure gradient across the aortic valve around $60 \%{ }^{6}$. Even though this procedure has shown promising results, 
reintervention following aortic balloon valvuloplasty is high due to several factors, including restenosis in one third of the patients ${ }^{6}$. Recent studies have shown that in vascular endothelial cells, flow patterns are critical in the sense that they influence the initiation of atherosclerosis, in-stent restenosis, and bypass graft failure. After balloon valvuloplasty, there is a relief in the pressure gradient across the aortic valve, however the hemodynamics do not resemble that of a normal valve, which could play an important role in the cause of restenosis. Valvular leaflet remodeling has been traced to endothelial cell dysfunction and denudation ${ }^{2}$, which is the primary suspect for the cause of restenosis in patients with balloon valvuloplasty. Valvular endothelial cells, like vascular endothelial cells, are known to remodel in response to hemodynamic environments by sensing the mechanical signals, and reorganizing the cytoskeletal filaments and the focal adhesion complexes ${ }^{2}$. The process by which valvular endothelial cells remodel after balloon intervention is not well known. By evaluating the changes in valvular endothelial cells' intracellular structural proteins in response to flow profiles following balloon intervention, we can delineate potential abnormal responses, which could be linked to the underlying cause of rapid restenosis after balloon implantation.

The need for reintervention after balloon valvuloplasty is very common, eventually leading to surgical valve repair or valve replacement. Tissue engineering heart valves (TEHVs), based on bone marrow stem cells (BMSCs) and biodegradable scaffolds, have been investigated as the next step to current prosthesis limitations, particularly the lack of somatic growth, which is critical in the pediatric patient population ${ }^{7}$. BMSCs are a promising cell source due to their accessibility and phenotypic plasticity under 
biochemical and mechanical stimulation. TEHVs have shown a resemblance in the trilayer structure found in the heart valve; however structural differences such as the absence of surface ridges in TEHVs are evident and may contribute to the early failure of these constructs ${ }^{8}$. Recent studies have shown that shear stress can regulate the proliferation and differentiation of BMSCs through a variety of signaling pathways ${ }^{9}$. Heart valves experience mechanical stresses, including cyclic flexure, tensile, and fluidinduced shear stress patterns, such as oscillatory shear stresses (OSS), during their lifetime ${ }^{10}$. It was previously demonstrated that coupled flexure and flow environments augmented tissue formation using PGA:PLLA scaffolds seeded with BMSCs ${ }^{11}$. At the intracellular scale, changes in BMSC cytoskeleton have also been observed when BMSCs were exposed to fluid induced shear stress. Alterations in F-actin structure and distribution may thus be closely linked to gene expression and protein synthesis in the mechanobiology of stem cells ${ }^{2}$. In addition, we believe that focal adhesion patterns are important to observe, as they sense mechanical forces and act as conduits for translating these physical forces into chemical and genetic cellular responses. OSS may also further regulate BMSC structure, hence its phenotype specifically towards the valvular lineage. In this investigation, we are going to apply OSS to growing valvular endothelial cells and BMSCs to understand their structural changes to this environment, which would subsequently have implications to the underlying cellular basis for restenosis and for optimizing heart valve tissue engineering protocols, respectively 


\section{SPECIFIC AIMS}

Specific Aim 1: To compare changes in the hemodynamic environment after balloon valvulplasty compared to a normal patient using a computational fluid dynamic model (ANSYS CFD).

Specific Aim 2: To observe changes on F-actin and nuclear deformation on bone marrow stem cells when exposed to pulsatile flow, steady flow, and no flow environments. 


\section{CHAPTER II- LITERATURE REVIEW}

\section{Composition of the Aortic Heart Valve and Function}

The aortic heart valve is composed of three leaflets, which open and close during systole and diastole respectively. Over a single lifetime, hear valves will open and close at least $3 \times 10^{9}$ times (sacks 2015, heart valve function). The tissue and cells that constitute the leaflets must have unique characteristics that allow them to open and close properly, as well as remodel as needed ${ }^{4}$. The leaflets are comprise of three different layers, which include the fibrosa (facing the artery), ventricularis (facing the ventricle), and the spongiosa, which is located between the fibrosa and the ventricularis, each containing different cells and molecules and each experiencing different fluid flow profiles ${ }^{7,12}$ (Figure 1). The ventricularis surface is exposed to a high velocities and unidirectional shear stress, while the fibrosa side undergoes through OSS and lower velocities ${ }^{13}$. The ventricularis side is composed of elastin, which is radially aligned, and collagen, with an isotropic alignment. On the other hand, the fibrosa is longitudinally aligned collagen fibers. The spongiosa, consists with glycosaminoglycan and proteoglycan, create a shear slip buffer zone during leaflet movement ${ }^{12}$. These three layers provides the tensile strength the valves need in order to resist the mechanical forces being exerted ${ }^{14}$. The leaflets composition and structure allow them to endure demanding mechanical forces as they function under a complex of cyclic tensile-flexure-shear stress, such as oscillatory shear stress (OSS), loading environment ${ }^{3,14}$. During the cardiac cycle the heart pumps

about 3-5 liters of blood every minute through the valves ${ }^{15}$ which results in transvalvular pressures of $10 \mathrm{mmHg}$ in the pulmonary valve and $80 \mathrm{mmHg}$ in the aortic valve, as well as 
shear stress estimated values of $10-80$ dynes $/ \mathrm{cm}^{2}$ on the aortic valve ${ }^{16}$. The aortic valve, needing to withstand very demanding and complex mechanical stress, makes it difficult for prosthesis to endure without causing health risks on the patient.

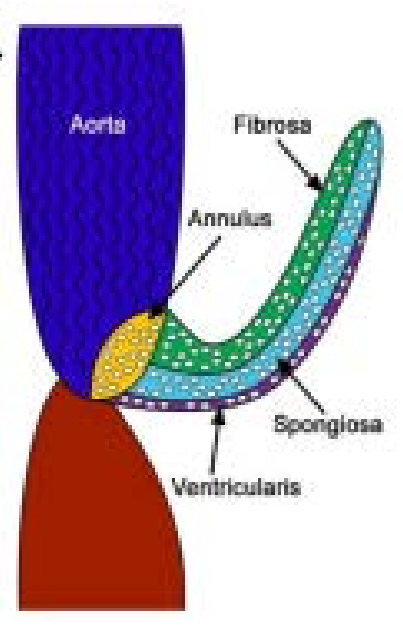

Figure 1. Heart valve composition showing fibrosa, spongiosa, and ventricularis. (Wirrig, 2013)

\section{Valvular Endothelial Cells (VECs)}

The leaflets are also composed of valvular endothelial cells (VECs) and of valvular interstitial cells (VICs). Endothelial cells, lining most of the organs, carry many critical function for blood and tissue homeostasis ${ }^{3}$. There are three main roles carried out by valvular endothelial cells: regulation of coagulation, regulation of underlying interstitial cells, and the diffusion or clearance of threatening agents from the blood ${ }^{3}$. It is well established that the endothelial cells are the first responders to tissue damage, controlling coagulative response to ensure clotting during injury. VECs have also shown to express von Willebrand factor, a blood glycoprotein involved in homeostasis, and also modulate the expression of factors involved in coagulation in response to shear stress ${ }^{3}$. However 
the dysfunction of VECs can result in many clinical conditions such as inflammatory reactions, calcification and blood clots ${ }^{17}$.

As stated previously, shear stress is one of the main mechanical stresses found in blood vessels and heart valves. Butcher et al. has previously shown that there are morphological and behavioral differences between VECs and aortic endothelial cells due to the different biomechanical environments they are exposed to $^{2}$. Several groups have studied the effect of shear stress on endothelial cells, and have demonstrated that VECs respond differently by orienting perpendicular to flow and parallel to the circumferentially aligned underlying tissue ${ }^{3}$; whereas vascular endothelial cells align parallel to flow regardless matrix orientation ${ }^{18}$. VECs do not only show phenotypic differences from vascular endothelial cells, they also express different genes as a response to fluid induced shear stress. Aortic endothelial cells show an increase expression of proinflammatory genes such as interlukins, connexin 43, BMP-4, and Collagen type II, all of which have been shown to contribute to vascular endothelial cell inflammatory atherosclerosis. On the other hand, VECs have shown a more abundant expression of anti-inflammatory genes and a less abundant expression of pro-inflammatory genes, suggesting that VECs may be innately more anti-inflammatory than aortic endothelial cells ${ }^{19}$. Previous studies have also shown that VECs are more proliferative than aortic endothelial cells ${ }^{20}$.

One of endothelial cells unique characteristics is the ability to change from VECs to a contractile myofibroblast-like VICs, a process called endothelial-mesenchymal transformation (EMT) ${ }^{21}$. EMT has been shown to begin with endothelial cells losing cellcell contact and separating from the monolayer. Subsequently losing endothelial markers 
and gaining mesenchymal markers, and migrating to the interstitial space ${ }^{22}$. Balachandran et al reported to induce endothelial cells to undergo EMT by applying a pathological cyclic strain, suggesting that mechanical strain does regulate EMT in a directionally dependent manner ${ }^{21}$.The role of EMT in the adult heart valve is not well known, however it is a critical event for embryonic development of the heart valve ${ }^{23}$ (Figure 2).

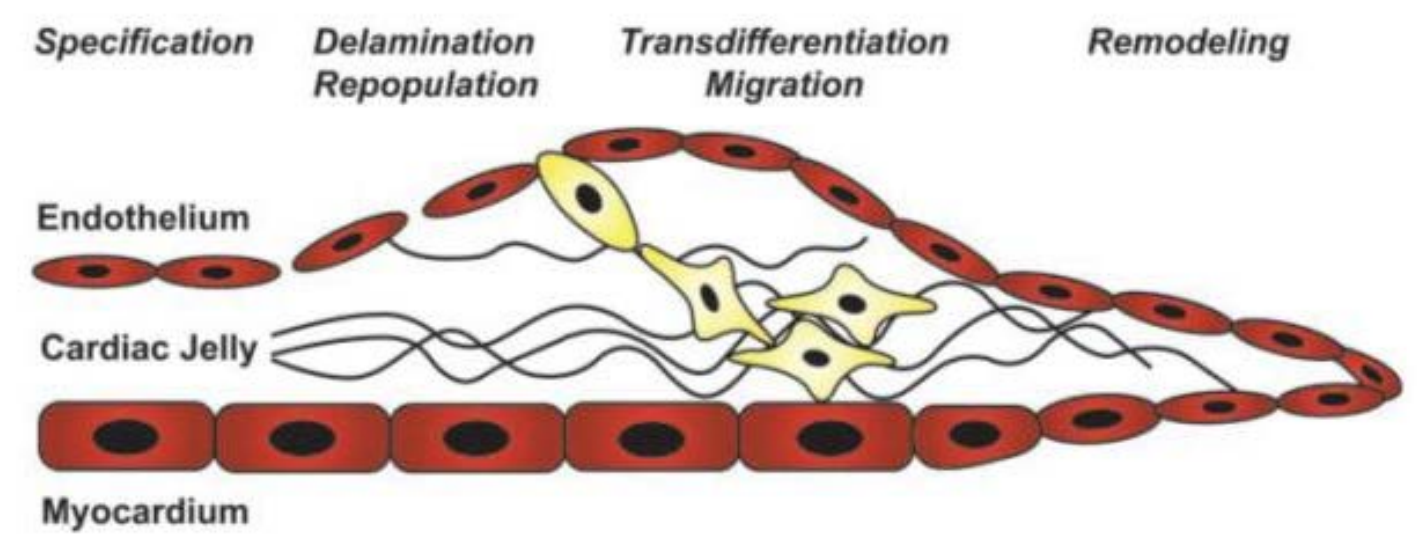

Figure 2. EMT process during heart valve formation. Endothelial cells going through EMT and migrating into the interstitial space (cardiac jelly) (Bischoff, 2007)

\section{Valvular Interstitial Cells (VICs)}

VICs are the most prevalent cell in the heart valve and are found in all three layers of the valve $^{24}$. The interstitial cells are made up of fibroblasts, smooth muscle cells, and myofibroblast which share the characteristics as smooth muscle cells and fibroblasts ${ }^{25}$. VICs main function is to maintain the structural integrity of the leaflets by constantly remodeling the tissue and by secreting matrix metalloproteinases. The dualistic mode for VICs is not well understood, however it is thought that the phenotype associated with smooth muscle actin is involved in proliferation and migration. Furthermore, the 
contractile phenotype found on these cells is associated with the remodeling of the extracellular matrix ${ }^{26}$. In vivo studies have suggested that VICs produce high amount of proteins and glycosaminoglycans ${ }^{17}$.

It has been established that pulsatile hemodynamic shear stress, which found in the heart valve, affects VICs through VECs as well as through other pathways including matrix shear stress ${ }^{24}$. When VICs are applied a mechanical force they respond by altering cellular stiffness and by producing matrix component ${ }^{24}$. Recent studies have shown collagen production of VICs after being subjected to stretching forces, however the type of collagen being produced was dependent on the level of the stretch. Collagen III gene expression increased as the level of stretch increased as well ${ }^{24}$. Mechanical stresses, sensed initially by VECs, are transduced by same to regulate VICs through paracrine signaling. VECs also stimulate a decrease in VICs proliferation, an increase in protein synthesis with shear stress, and a reduction of glycosaminoglycan loss under flow ${ }^{24}$.

\section{Aortic Heart Valve Hemodynamics}

The hemodynamic environment surrounding the heart valve, controls and ensures its proper functionality. The heart valves, as previously mentioned, are exposed to different mechanical stresses including, high levels of cyclic flexure, stretch and fluid-induced, oscillatory shear stresses (OSS). Wall shear stress (WSS) is considered the most important hemodynamic parameter for endothelial cells, defined by the following equation: $T_{w}=4 \mu Q / \pi R^{3}$. Q is the volume flow rate, $\mu$ is the viscosity and $R$ is the radius

of the vessel. In blood vessels, the mean wall shear stress reported is believed to be 10-20 dynes $/ \mathrm{cm}^{2}$. However, WSS on the heart valves are difficult to obtain, and several groups 
have reported figures ranging from 20 dynes $/ \mathrm{cm}^{2}$ to 1000 dynes $/ \mathrm{cm}^{2}{ }^{3}$.In healthy heart valves, the peak blood velocity, occurring at peak systole, on the aortic heart valve has been shown to be $1.35 \pm 0.35 \mathrm{~ms}^{-127}$. However, due to the fact that each side of the leaflet experience different velocity gradients, we would expect them experiencing different shear stresses as well. The fibrosa side of the leaflet undergoes pulsatile unidirectional shear stress, and the ventricularis undergoes oscillatory shear stress (OSS) caused by vortices present on this side of the leaflet. These vortices are thought to facilitate the movement of the leaflets to a close position during diastole ${ }^{25}$.

In addition to WSS, we have other mechanical components affecting the heart valves: flexure and stretch. Valvular leaflets are stained in a biaxial pattern, having peak circumferential trains of approximately $10 \%$ and radial strain of more than $40 \%{ }^{28,29}$. When opening, leaflets also experience a high degree of flexure, resulting in a compressive strain in the fibrosa side and a tensile strain in the ventricularis side ${ }^{30}$. Thus, the fibrosa and the ventricularis undergo different mechanical stress patterns which could affect the behavior of the endothelial and interstitial cells. However due to the composition of the heart valves, they are able to withstand high mechanical stresses.

\section{Heart Valve Disease}

Heart valve diseases include, heart valve regurgitation, stenosis, and atresia. Regurgitation occurs when the valve doesn't close tightly causing blood to flow back into the ventricle. Atresia consists of lacking an orifice or having the orifice abnormally closed, preventing blood to pass through. In the case of stenosis, which is the most 
common condition in heart valve disease, involves the thickening and hardening of the heart valve preventing the valve to fully open during the cardiac cycle (Figure 3).

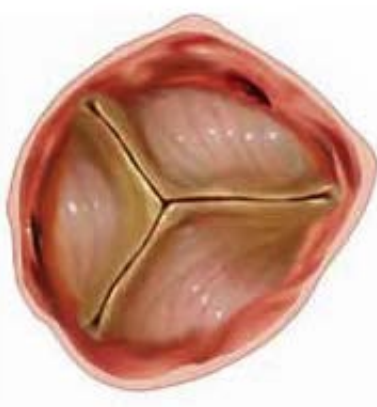

Normal Valve

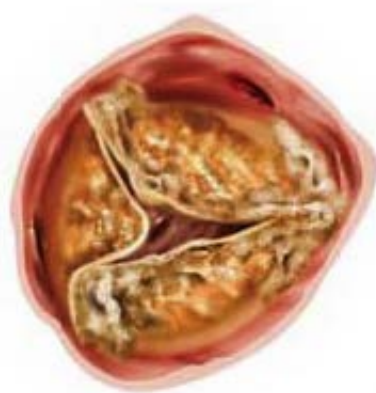

Stenotic Valve

Figure 3. The composition of a normal heart valve and a stenotic heart valve (USC, 2012).

There are people who are born with this condition, congenital heart valve stenosis, whereas other people develop AVS through their lifetime. Aortic valve stenosis (AVS) was considered a "wear and tear" degenerative conditions which resulted in the formation of calcium deposits in the heart valves. However, new evidence have shown that AVS can be developed as part of a complex, regulated series of processes similar to atherosclerosis $^{31}$. As in atherosclerosis, the damaging of the endothelial layer due to an increase in mechanical stresses, is thought to be the initial event for developing AVS. Following endothelial injury, the same lipids involved in atherosclerosis, are shown to be involved in heart valve calcification, in particular oxidized low-density lipoprotein cholesterol (LDL) and lipoprotein $\mathrm{A}^{32}$. The lipid oxidation then establishes an inflammatory response by recruiting macrophages, $\mathrm{T}$ lymphocytes and mast cells ${ }^{32}$. At 
this stage, studies have shown the initiation of calcium deposition in the area of injury, which has been associated with cell death. Apoptotic bodies have demonstrated to have similar characteristics as matrix vesicles found in bone ${ }^{32}$. Thus the formation of aortic stenosis has been associated with inflammation and lipid deposition.

Endothelial damage can be caused by several factors, including abnormal hemodynamics and tissue mechanics ${ }^{3}$. It has been previously shown VECs undergoing physiological shear tress values, respond by expressing anti-inflammatory genes, however when they are exposed to abnormal fluid flow shear stress there was an activation of inflammatory mediators $^{33}$. Studies have also shown the activation of calcification genes, chondrogenic genes, after VECs have been exposed to abnormal shear stresses ${ }^{33}$. Besides inducing the cells to express calcific genes through shear stress, other studies have also shown an increase in calcific gene expression when VECs are exposed to high levels of strain, another innate mechanical force found in heart valves.

Yoganthan et al. has previously shown an even distribution of flow field during peak systole on a normal heart valve with maximum velocity of $1.2 \mathrm{~ms}^{-1}$, while a jet-type flow field with maximum velocity of $7.0 \mathrm{~ms}^{-1}$ was observed in a stenotic valve ${ }^{34}$. In the stenotic heart valve, Yoganthan also observed a high turbulent shear layer around the heart valve which could cause damage to the blood elements and the endothelial cells lining the valve and the walls ${ }^{34}$.

\section{Heart Valve Tissue Engineering}

The replacement of the diseased heart valve, is not a common procedure done in order to enhance the survival and quality of life of the patients. Current mechanical and 
bioprosthetic heart valves give the patient 15-20 years of adequate function in adults ${ }^{3}$. However, the mechanical heart valves are prone to inflammation, infection and thrombosis, while the bioprosthetic heart valves experience calcification on the valve cusps, leading to regurgitation and reduced orifice area ${ }^{35}$. Furthermore, in the pediatrics application, reoperation are required in order to accommodate larger valve diameters as they grow older. Tissue engineered heart valve (TEHV) has a great potential to generate suitable viable heart valve replacement, and overcome the risks associated with mechanical and bioprosthetic heart valves. The ideal heart valve is characterized as a non-thrombogenic, viable living tissue that lasts the lifetime of the patient, providing remodeling and repair of injuries and potentially allows somatic growt ${ }^{25}$.

The approach that most groups are implementing is the seeding of cells into a biodegradable scaffold, and culturing the construct under appropriate environmental cues to induce tissue formation, and then implanting these pre-conditioned constructs in vivo $^{35}$. Hoerstrup et al. pre-conditioned the construct using a pulsatile flow bioreactor device and implanted the constructs into six lambs ${ }^{36}$. Through echocardiogram, the leaflets were shown to function correctly without stenosis, thrombus or aneurysm up to 20 weeks. They also revealed a layer of cuspal tissue with collagen and elastin, and covered by endothelium. Other groups have been using mesenchymal stem cells and the biodegradable scaffold PGLA/PGA for TEHV. Mesenchymal stem cells, due to their accessibility, self-renewal properties, and phenotypic plasticity under biochemical and mechanical stimulation, are a promising cell source for tissue engineering. Sutherland et al. has previously used ovine bone marrow stem cells to construct an autologous 
semilunar heart valve, which showed deposition of extracellular matrix and distribution cell phenotypes reminiscent of that in a native pulmonary heart valve, after implantation in a sheep ${ }^{37}$. We have previously created a construct using PGA/PLLA and BMSCs cultured under flex-flow conditions in a bioreactor. We observed BMSC differentiation and migration within the engineered tissue, leading to cells expressing endothelial markers lining the surface, and cells expressing myofibroblast-markers within the tissue, resembling the cell distribution in a native heart valve.

These advances can help us understand the multiscale hierarchical arrangements typically found in heart valves, and therefore develop viable tissue engineered heart valves. 


\section{CHAPTER III: STEM CELL STRUCTURAL ADAPTATION TO FLOW: IMPLICATIONS FOR VALVULOGENESIS}

Bone marrow stem cells (BMSCs) have been implicated in the development of heart valve tissue engineering. OSS, a mechanical force present in heart valves, has been shown to differentiate BMSCs into a cell showing endothelial cells markers. Furthermore, OSS coupled with flexure has shown an increase of valvular endothelial cells markers on BMSCs suggesting a potential differentiation of these cells. The differentiation of stem cells has been linked to changes in actin filaments, causing a change in gene expression. We previously observed the effects of oscillatory shear stress (OSS) on the BMSC cytoskeleton after terminal chemical fixation of the cells. The alterations in BMSC cytoskeleton during OSS has not yet been understood. Thus, in this study we applied OSS to growing BMSCs to understand fundamental cellular structural responses that precede the resulting gene expression, in the context of the heart valve phenotype. By identifying these changes a deeper understanding of specific changes at the cell structural-level, could be achieved and potentially fine tune the flow conditions to achieve an optimized valvular phenotype.

\section{INTRODUCTION}

Critical valvular heart disease is a serious cardiovascular complication ${ }^{38}$. In infants, congenital heart defects occur in four to six infants for every 1000 births ${ }^{39}$. Approximately $24.5 \%$ of neonatal mortality is attributed to congenital heart defects ${ }^{40}$. Among the plethora of cardiovascular defects, one of the more common, yet lifethreatening conditions is critical aortic valve stenosis (AVS), which results in high mortality and morbidity despite early intervention ${ }^{41}$. Under normal circumstances, valve 
leaflet composition and structure permits endurance of demanding mechanical forces as they function under a complex, coupled loading state of cyclic tensile, cyclic flexure-and fluid-induced shear stresses, including oscillatory shear stresses (OSS) ${ }^{2}$. However, in AVS, significant systolic transvalvular pressure gradients with a mean $>60 \mathrm{mmHg}$ resulting from narrowing of the aortic root imposes considerable workload on the left ventricle, resulting in rapid heart failure if left untreated ${ }^{17,35,42}$. Intervention to relieve aortic valve stenosis in the neonate is usually approached via balloon dilation of the aortic valve, performed through an interventional cardiac catheterization (balloon aortic valvuloplasty/BAV). Although the short term results are beneficial usually leading to relief of the narrowed structure and temporary avoidance of the consequent left ventricular failure, mid to long term prognosis is variable ${ }^{41}$. Moreover, sizing limitations, risks associated with anti-coagulant use in children, accelerated calcification and an inability to accommodate somatic growth severely limit use of commercially available prosthetic valves for replacement of the infant's stenosed valve.

Over the last ten years, tissue engineered heart valves (TEHVs) derived from stem cells have been investigated to overcome the shortcomings associated with treatment of critical valve anomalies in children. Recent studies have applied mechanical stimuli, to construct superior tissue structures with properties resembling native heart valves, in particular, using bone marrow-derived stem cells (BMSCs) seeded onto biodegradable scaffolds ${ }^{11,37}$. BMSCs are a promising cell source due to their accessibility, self-renewal properties, and phenotypic plasticity under biochemical and mechanical stimulation. Stem cell differentiation using growth factors, molecular inhibitors, and biochemical cues have been extensively studied, however the mechanotransduction regulatory pathways in stem 
cell differentiation remains uncertain ${ }^{43}$. Mechanical loads have shown to play an important role in the development, growth, and maintenance of tissue functions, such as the remodeling of cardiovascular tissues and bone formation ${ }^{44}$. Recent studies have demonstrated that fluid-induced shear stresses can regulate mesenchymal stem cell migration and stimulate stem cell differentiation into different cell lineages, including osteoblasts and endothelial cells (ECs) ${ }^{45}$. However, the effect of mechanical forces in the context of stem cells used in heart valve tissue engineering, where the mechanics play a foundational role, is yet to be delineated. Nonetheless, a few pertinent, landmark studies are summarized as follows: It was previously demonstrated that coupled flexure and flow environments augmented tissue formation using PGA:PLLA scaffolds seeded with BMSCs $^{11}$. Elsewhere, Sutherland et al utilized BMSCs isolated from ovine and PGLA/PGA biodegradable scaffolds to make autologous semilunar heart valves, which were later implanted in sheep, and subsequently showed extracellular matrix and distribution of cells in the engineered valve were similar to native heart valves ${ }^{37}$. However, structural differences such as the absence of surface ridges in TEHVs were evident and were thought to potentially result in early failure of these constructs ${ }^{11}$. Mechanical stimuli are sensed by the cell membrane receptors which are later transferred to the cytoskeleton; consequently this initiates a biochemical signaling cascade ${ }^{19}$. In BMSCs, the cytoskeletal structure has shown to be altered after exposure to fluid-induced shear stress ${ }^{46}$. Fundamental changes in actin structure and distribution may thus closely be linked to gene expression and protein synthesis in the shear stress stimulation of stem cells ${ }^{3}$, similar to $\mathrm{ECs}^{47}$. The actin filaments of the cell cytoskeleton serve as structural contributors to modulation of subsequent cell biological responses, including gene 
expression, cellular and matrix protein synthesis. In general, it has been shown that the application of mechanical stress on actin filaments causes cytoskeleton reorganization leading to tissue remodeling affecting stem cell viability, self-renewal, and differentiation ${ }^{48}$, although detailed characterization of intracellular structures specifically in response to fluid-induced shear stress is not known. In addition, other cellular components such as focal adhesions, integrins, and the nucleus collectively play important roles in modulating cellular biological responses ${ }^{37}$. For example, the connection between the matrix and the cytoskeleton allows the cell to transmit external forces to the cell's nucleus, thus triggering biochemical signals such as the synthesis of signaling proteins ${ }^{49}$.

We previously observed the effects of oscillatory shear stress (OSS) on the BMSC cytoskeleton after terminal chemical fixation of the cells ${ }^{50}$. OSS regulates BMSC structure and has been shown to be highly relevant to native heart valve development and to TEHVs ${ }^{51}$. However, as was previously stated, the fluid-induced, OSS-related structural changes that precede BMSC phenotypic switching and matrix production are not known. Yet, identifying alterations in the BMSC cytoskeleton during OSS exposure may lead to a deeper understanding of specific changes at the cell structural-level, that lead to differential regulation, which in turn can be used to fine tune the flow conditions to achieve an optimized valvular phenotype. Thus, in this investigation we applied OSS to growing BMSCs to understand fundamental cellular structural responses that precede the resulting gene expression, in the context of the heart valve phenotype. These efforts are novel and unusual in that OSS is a relatively lesser known mechanical stimulus which to our knowledge has never been applied in order to identify the structural responses of 
BMSCs; yet such a study is highly relevant to heart valve tissue engineering developments.

\section{METHODS}

\section{Culture and Expansion of BMSCs}

Approximately 5x10 $10^{5}$ BSCs/mL (Fisher Scientific, Pittsburgh, PA) were cultured in T75 vented cell culture flask using AdvanceStem Mesenchymal Stem Cell Medium (GE Healthcare Hyclone, Logan, UT) with 10\% mesenchymal stem cell growth supplement (GE Healthcare, Malborough, MA) and 1\% penicillin and streptomycin (Fisher Scientific, Waltham, CA) for growth and expansion. Cells were grown in a standard cell culture incubator operating with $5 \% \mathrm{CO}_{2}$ at $37^{\circ} \mathrm{C}$ with $95 \%$ humidity. BMSCs culture expanded to passages 4 to 6 were utilized for subsequent studies.

\section{BMSC Transfection}

BMSCs were transfected for purposes of cell visualization with green fluorescent protein (GFP) via electroporation as previously described ${ }^{52}$. In brief, a density of $1 \times 10^{6}$ BMSCs were transfected using electroporation (Gene Pulser Xcell Electroporation System BIO-

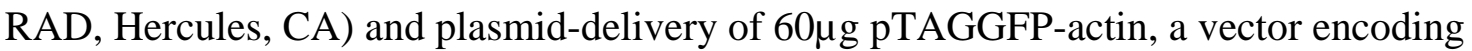
TagGFP fusion with actin used for labeling actin filaments in living cells (Evrogen, Moscow, Russia). The following settings were used for electroporation: Exponential Decay Pulse, Voltage of $350 \mathrm{~V}$, capacitance of $950 \mathrm{uF}$, and Resistance: of $200 \mathrm{ohms}^{52}$.

\section{Transfection Efficiency}

Cell viability and cell apoptosis was assessed using propidium iodide (PI) solution and Annexin protein respectively following manufacturer supplied instructions (Biolegend, 
San Diego, CA). In brief, two days following transfection, BMSCs were re-suspended in Annexin V Binding Buffer at a concentration of $2.5 \times 10^{5}$ cells $/ \mathrm{ml}$. PI was added to $100 \mu \mathrm{L}$ of cell suspension. After 15 min of incubation without light exposure, they were evaluated by flow cytometry (BD Bioscientific, San Jose, CA).

\section{Fluid-Induced Mechanobiology Experiments}

Transfected BMSCs were plated in Collagen Type I (Fisher Scientific) coated microchannels. A square wave was used in order to create a pulsatile flow environment to which the cells were going to be exposed to using a shear stress cell assay system (Fluxion Biosciences, South San Francisco, CA). Images of the cells under no flow, steady flow and OSS environments were acquired using fluorescent microscopy (Olympus IX81, CA) every hour for 5 hours for the first 2 days. After the second day, cells were monitored every 24 hours. Cells in the no flow, steady-state (SS) flow and OSS groups were cultured for a total of 3 days.

\section{Cell Structure Quantification}

Cell actin filaments and nucleus were quantified by analyses of images acquired during the time course of the cell culture experiments (ImageJ, NIH Image, Bethesda, MD). Actin filament quantification was performed using two metrics. The initial quantification was based on simple filament counting. For the second metric, the actin filament distribution and deformation were observed. Quantification of the cell nucleus was conducted by computing the nuclear eccentricity parameter. Nuclear eccentricity (circularity) is a measure of nuclear elongation and is in a range of $[0,1]$; a circle has an 
eccentricity of 1 whereas a more elongated shape would be associated with a lower number (ImageJ).

\section{Statistical Analysis}

One-way Anova followed by a Tukey’s post hoc test was conducted to test for any significant differences between the three groups: no flow, SS and OSS ( $\mathrm{n}=8$ wells/group; SPSS, V16, IBM, Armonk, NY). A statistically significant result was interpreted to have occurred when $\mathrm{p}<0.05$.

\section{RESULTS}

\section{Transfection Efficiency}

GFP Transfection was initially found to occur in $77.4 \%$ of the cells. (Figure 4). However of all the cells utilized, eventually $\sim 50 \%$ of the cells were found to be both viable and

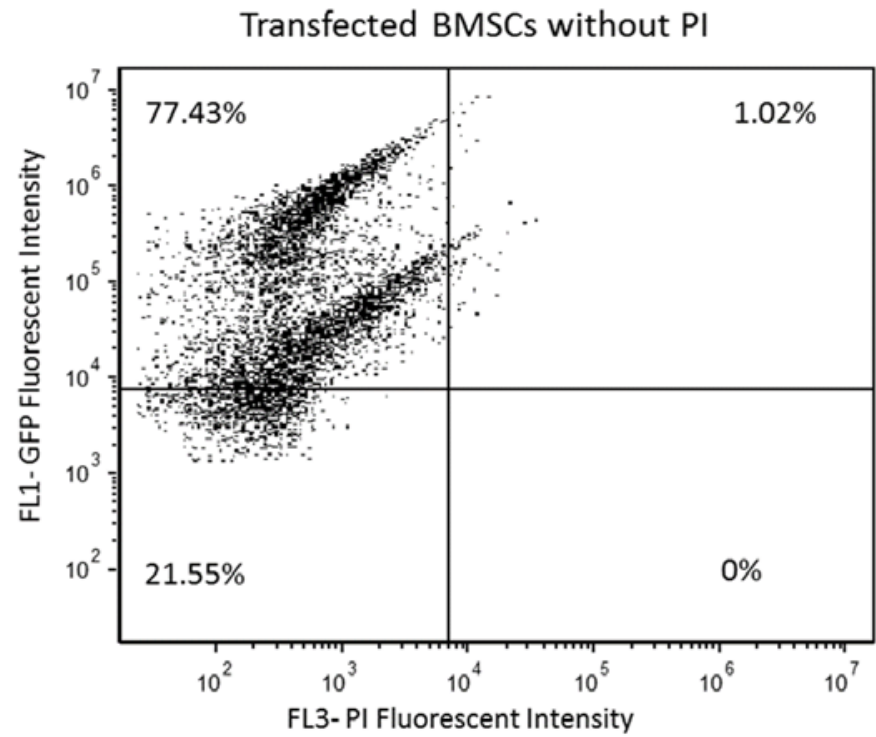

Figure 4. Transfected BMSCs with actin GFP were assessed two days after electroporation using flow cytometry; $77.43 \%$ of the cells were shown to express high GFP intensity as seen in the first quadrant. 
successfully transfected (Figure 5). Viable transfected were subsequently segregated from

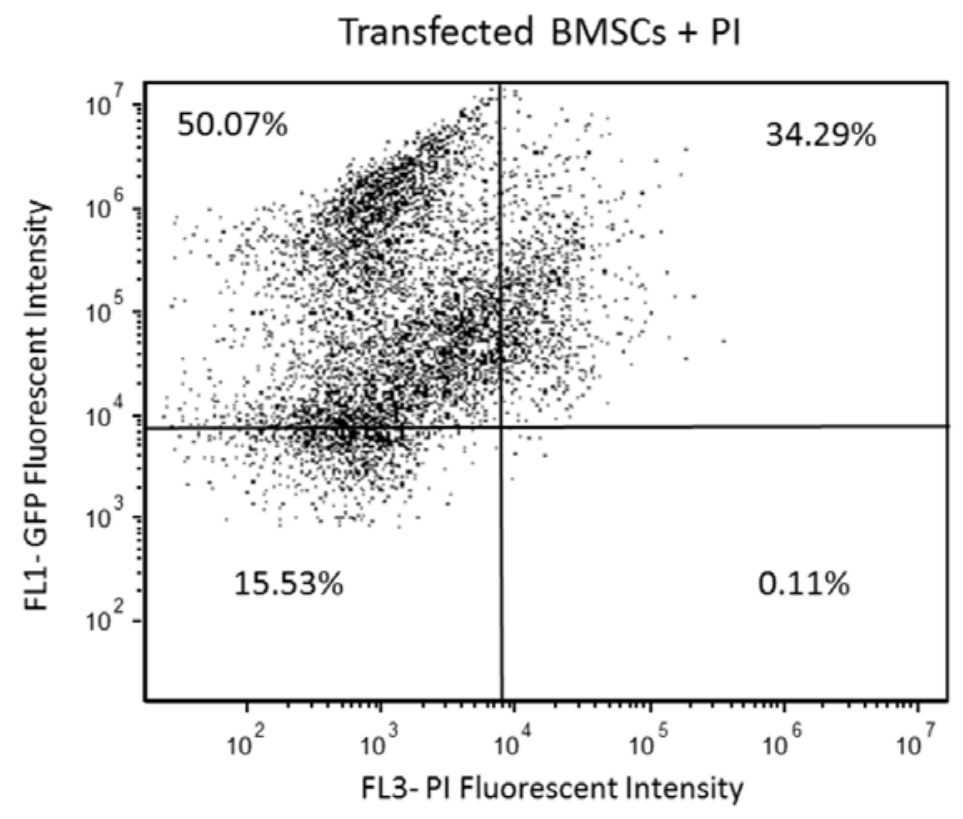

Figure 5. Transfected BMSCs with actin GFP assessed two days after transfection were incubated in propidium iodide (PI) solution to evaluate cellular viability; $50.07 \%$ of cells were efficiently transfected and viable after electroporation, as seen in

the general population for use in subsequent experiment.

\section{Number of Actin filaments}

BMSC actin filaments increased in number by $122.6 \%$ after 48 hours of OSS (Figure 6).

On the other hand, cells exposed to SS demonstrated only an $18.2 \%$ increase in the average number of filaments/cell after 48 hours of exposure, while the no flow group displayed a marginal changes. The average increase in the number of filaments in cells exposed to OSS compared to both SS and no flow groups was found to be significant ( $\mathrm{p}<$ 0.05). However, there was no significant difference in comparing the average number of filaments/cell between cells exposed to SS and no flow ( $p>0.05$ ). 


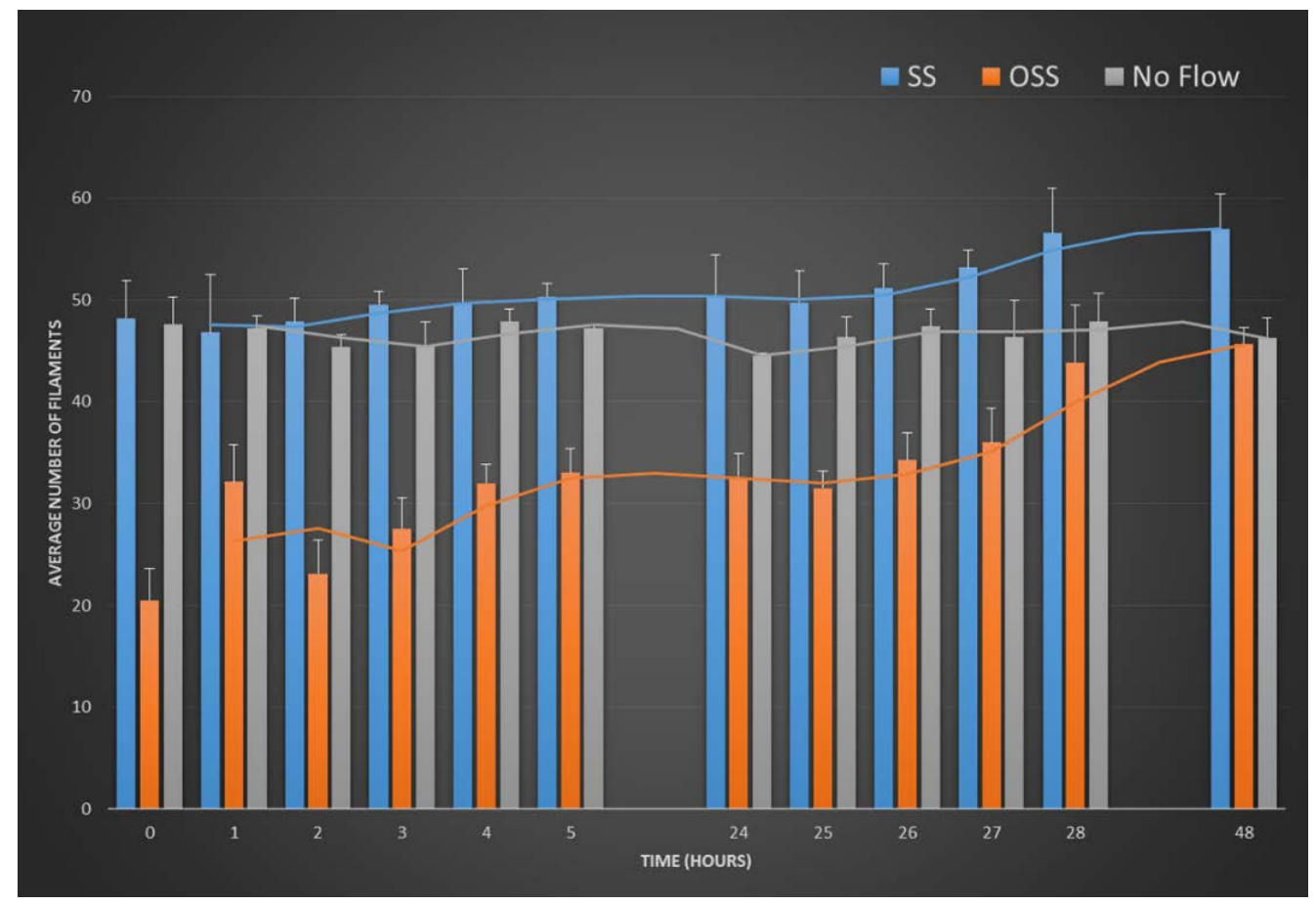

Figure 6.The effect of BMSC when exposed to OSS, SS, and No Flow (static) conditions on the number of actin filaments $(n=8$ wells/group).

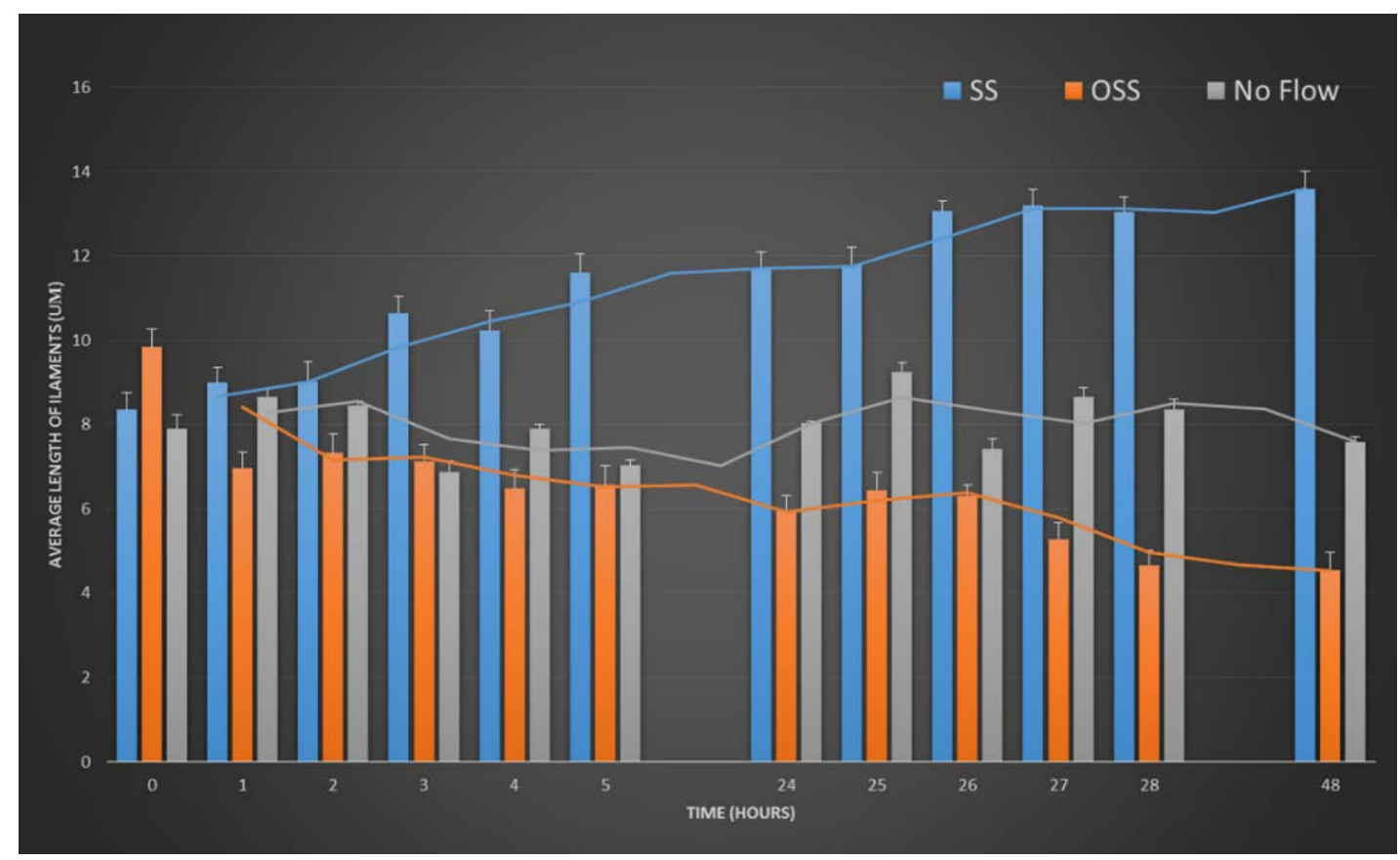

Figure 7. OSS, SS, and No Flow (static) conditions on average BMSC actin filament length ( $n=8$ wells/group). 


\section{F-actin filament length}

There was a 53.8\% decrease in the average length of the filaments after 48 hours in the cells exposed to OSS (Figure 7). On the other hand, there was a 19.5\% increase in average filament length on cells exposed to SS and marginal changes in cells in the no flow group. A significant decrease in the average actin filament length $(\mathrm{p}<0.05)$ in BMSCs exposed to OSS compared to cells in both the SS and no flow groups was observed.

\section{Nuclear Eccentricity}

We observed noticeable short term changes in nuclear shape in the SS and OSS groups during the first five hours after treatment compared to the no flow controls (Figure 8). However, after 48 hours, nuclear eccentricity was found to return to its original configuration and was not found to be significantly different amongst the no flow, SS and

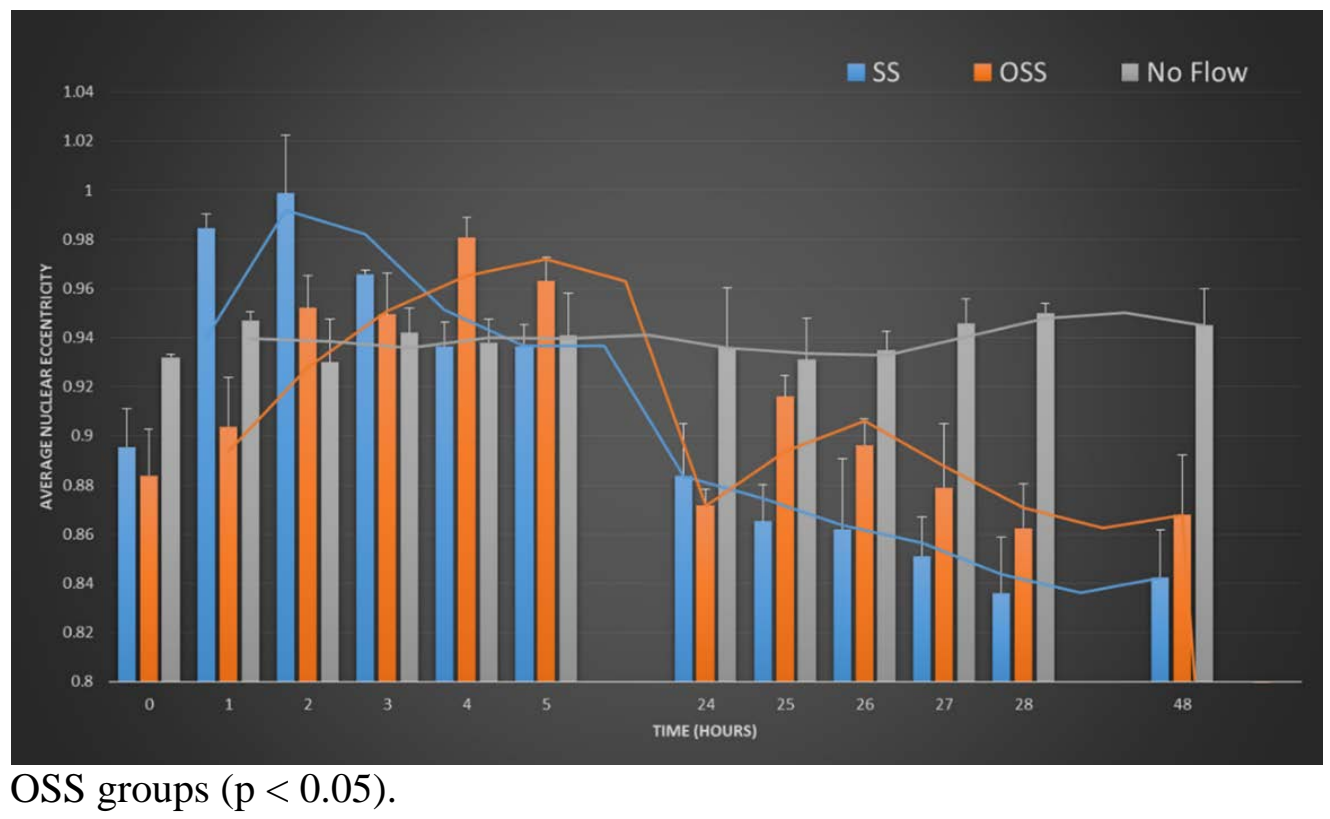

Figure 8. Nuclear eccentricity (circularity) in BMSCs while being exposed to OSS, SS, and No Flow (static) conditions ( $\mathrm{n}=8$ wells/group). 


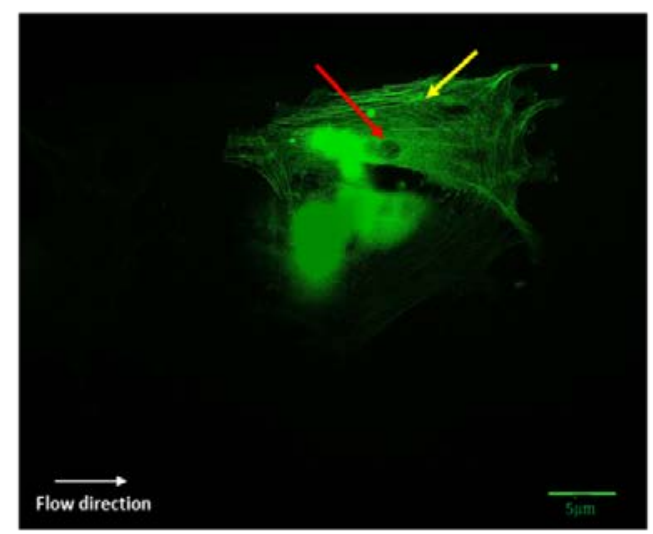

0 HRS

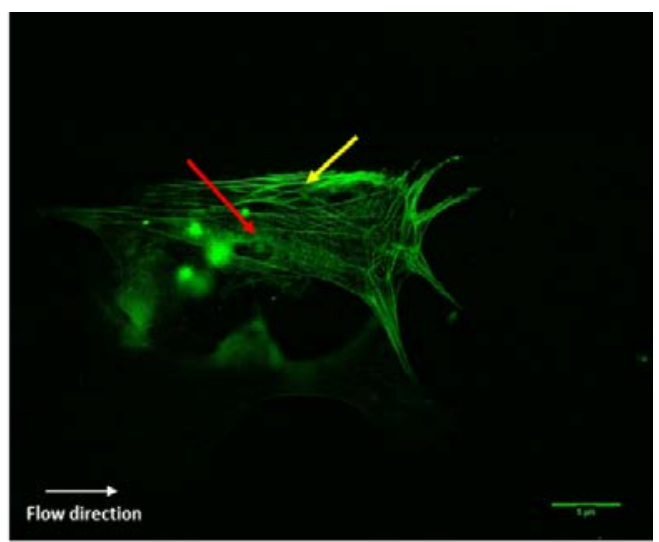

$48 \mathrm{HRS}$

Figure 11. Transfected BMSCs imaged at No Flow (static) conditions at 0 hours and at 48hours. Yellow arrows point to the actin filaments and red arrows show the nucleus

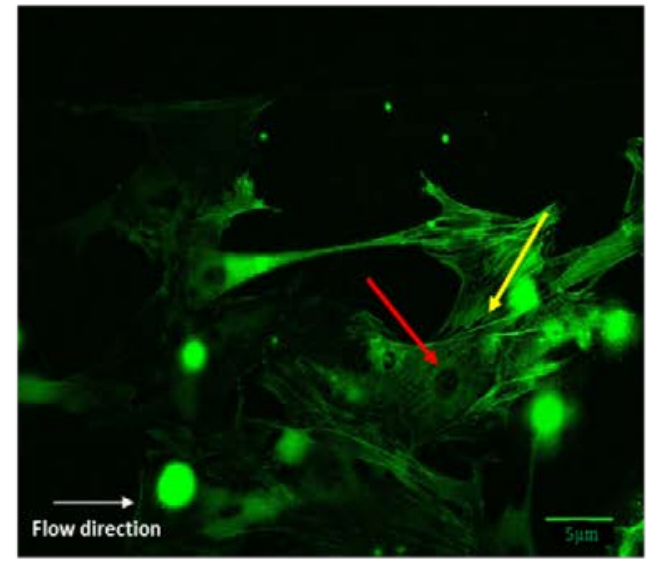

0 HRS

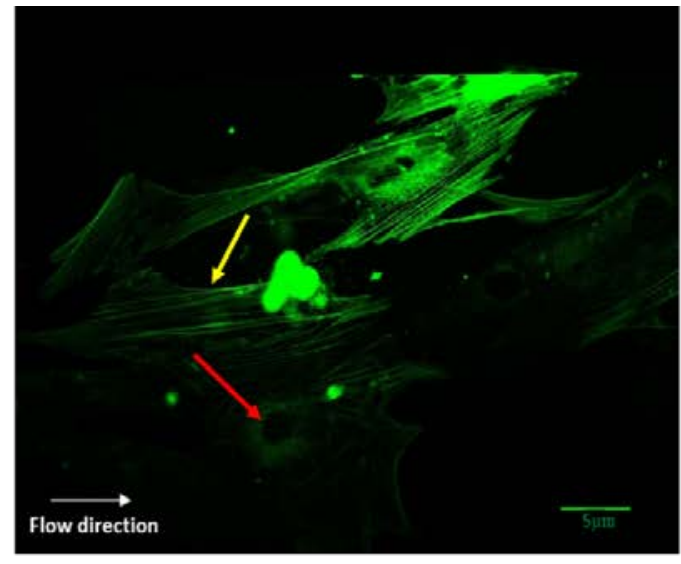

48 HRS

Figure 10. Transfected cells showing filament orientation at 0 and 48 hours. SS group.

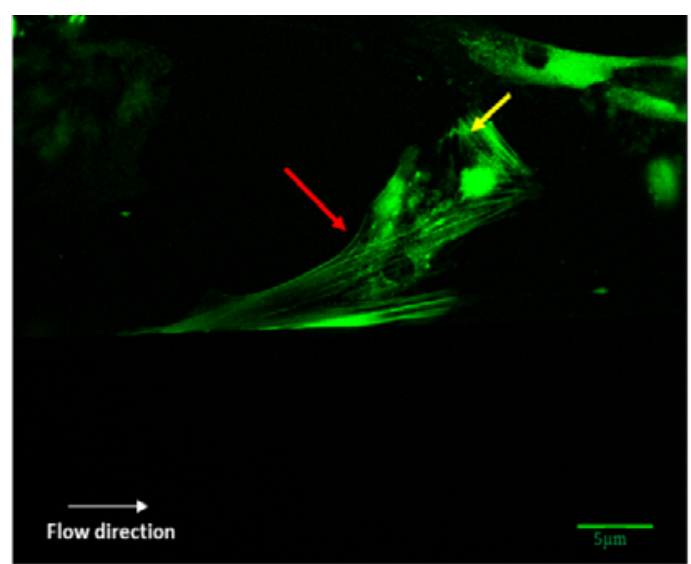

0 HRS

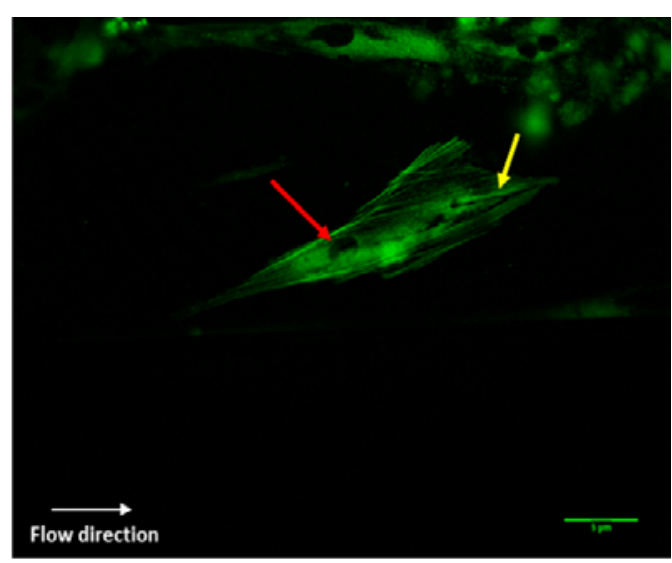

48 HRS

Figure 9. Transfected cells showing filament orientation under OSS. 


\section{DISCUSSION}

Pediatric patients suffering from congenital aortic valve anomalies such as a critical valvular stenosis have extremely limited treatment options. Balloon aortic valvuloplasty is typically performed longitudinally to relieve the narrowing and eventually the patient may undergo a total valvular replacement with a prosthetic device. Unlike prosthetic heart valves, TEHVs offer the possibility of overcoming the risks associated with artificial valve replacement in children and by offering the potential to support somatic growth. BMSCs remain a promising cell source because they promote tissue repair and can differentiate along cardiovascular and valvular pathways. Biochemical environments play a key role in determining cell fate and the differentiation of BMSCs. However, recent studies that have applied mechanical stimuli to BMSCs clearly demonstrate that the resulting cellular cues regulate proliferation and cell differentiation events; chondrogenic, endothelial, as well as cardiomyocyte phenotypes have been observed ${ }^{15}$. BMSCs have been exposed to different mechanical stress states, such as tension, compression, and fluid-induced shear stress ${ }^{7}$. The application of tensile strain has been shown to result in an increased gene expression of bone markers, such as Runx2, alkaline phosphate (ALP), collagen type I (Col1), and bone morphogenic proteins (BMPs) ${ }^{7}$. Recent studies have also shown the effect of mechanical stretch on the differentiation of stem cells, resulting in an increase in ALP activity and extracellular matrix formation as well as phosphorylation of focal adhesion kinase (FAK) ${ }^{13}$. A fundamental response to mechanical stimuli can thus be observed within the cell cytoskeletal structure. For example, McBeath et al. demonstrated that mechanical signals influence stem cell fate through linkages between cell shape, cytoskeletal mechanics, and protein activation ${ }^{20}$. 
They disrupted the actin cytoskeleton using an actin-disrupting agent, cytochalastin D, and were able to observe differentiation of stem cells towards adipocytes, rather than osteocytes, suggesting a vital role of the cytoskeleton in the differentiation of stem cells towards an osteoblast lineage. Similar to tensile strain, fluid induced shear stress has also been shown to regulate osteogenic genes in $\mathrm{BMSCs}^{5}$. Specifically, upon exposure of BMSCs to OSS, cells demonstrated an increase in calcium mobilization, and an increase in expression of osteocalcin and osteopontin ${ }^{18}$. Furthermore, exposure of BMSCs to OSS also increased DNA methylation, a central cellular mechanism for modulating gene expression. We subsequently wanted to identify fundamental changes in BMSC structure to OSS as a precursor to cellular signaling activity and eventual gene expression. A priori knowledge of BMSC structural events leading to the valvular phenotype may be leveraged to optimize engineered heart valve tissues intended for subsequent animal studies or clinical translation. Such optimization is important in the context of enhancing mechanical and biological resilience of the engineered construct when subjected to the in vivo environment.

OSS is an innate mechanical state present on the surfaces of native heart valves and has been hypothesized to enhance valve coaptation ${ }^{26}$. We previously demonstrated that the actin filaments in BMSCs orient themselves parallel to the flow direction when exposed to OSS ${ }^{23}$. In this study we applied a mean OSS of 1 dyne $/ \mathrm{cm}^{2}$ and observed the changes in actin filaments and the nucleus over 48 hours. The BMSCs exposed to OSS and SS were found to orient themselves in the direction of flow (Figure 10, Figure 11) which is not unlike ECs which also orient themselves in this manner ${ }^{4}$. Moreover, we found a significant increase $(\mathrm{p}<0.05)$ in the average number of actin filaments (Figure 6) in 
BMSCs while being exposed to OSS (48 hours), which we speculate, could be a result of augmented focal adhesions (FAs). FAs play an important role in the force-mediated differentiation of stem cells ${ }^{28}$. At the same time it has been reported that the formation of FAs is rapidly activated by specific forces exerted on cells, thereby resulting in the generation of additional actin filaments ${ }^{28}$, which is indicative of what we observed here for the BMSCs exposed to OSS. This finding therefore suggests that OSS may serve as a more appropriate trigger of stem cell differentiation compared to uni-directional shear stress. In particular, OSS may promote BMSC differentiation towards the cardiovascular and valvular cell types as it is blood or fluid-induced and therefore highly relevant to these phenotypes. We also observed a significant difference $(\mathrm{p}<0.05)$ in the average length of actin filaments between the OSS and SS groups (Figure 7). We speculate that the dramatic decrease in the length of actin filaments in BMSCs exposed to OSS could be a result of the activation of cofilin, an actin-binding protein which disassembles actin filaments ${ }^{23}$. The context of this process is the similar response of endothelial cells to fluid shear stress that results in dissociation of actin filaments, thereby permitting cellular alignment to flow ${ }^{23}$. Therefore, we speculate that a decrease in actin filament length under OSS states to be a triggering event for mesenchymal to endothelial transformation, an important process in promotion of an endothelium in the tissue engineered heart valve. We have previously demonstrated that in fact, OSS states do augment the endothelial phenotype in in vitro dynamically cultured engineered valvular tissues ${ }^{24}$. Note that SS conditions resulted in an increase in filament length (Figure 7) which may indicate reduced actin disassembly and hence, more restrictive differential regulation of BMSCs compared to OSS. 
In conclusion, we presented the changes in F-actin filaments and nuclear deformation responses of BMSCs to OSS, SS and no flow conditions over a period of 48 hours. Structural changes and differences were clearly observed between the groups. Specifically, OSS-conditioned cells responded with a substantial increase in the number of actin filaments but a considerable decrease in the length of the filaments. These events could serve as structural precursors that may differentially regulate BMSCs towards a valvular phenotype. On the other hand, we did not observe a significant difference in the nuclear shape among the OSS, SS and no flow groups; however further studies need to be conducted to determine the effects of fluid-induced nuclear deformation on BMSC differentiation. Even though our results are preliminary, our study provides a simple, yet unique perspective on specific cytoskeletal changes, particularly under OSS states that could regulate stem cell fate in a manner conducive for engineering valvular tissues. Nonetheless, further studies will be needed to confirm a direct correlation between the cytoskeletal changes observed here to the differentiation and gene expression activity of BMSCs. 
CHAPTER IV: OBSERVING CHANGES IN HEMODYNAMICS OF A HEALTHY HEART VALVE AND A TREATED HEART VALVE USING A COMPUTATIONAL MODEL

\section{INTRODUCTION}

Congenital heart defects are the most common birth defects, with about $1 \%$ of the population being affected by them ${ }^{4}$. One of the most severe being critical aortic valve stenosis (AVS), a life-threatening condition with high morbidity despite early intervention. In AVS, significant systolic transvalvular pressure gradients with a mean > $60 \mathrm{mmHg}$ resulting from narrowing of the aortic root imposes considerable workload on the left ventricle, resulting in rapid heart failure if left untreated ${ }^{3,35,42}$. Open surgical valvotomy and a less invasive procedure, transcatheter balloon valvuloplasty of the aortic valve, are two of the most used and recognized procedures done in neonates with AVS. Balloon valvuloplasty has been shown to reduce the pressure gradient across the aortic valve around $60 \%{ }^{6}$. Even though this procedure has shown promising results, reintervention following aortic balloon valvuloplasty is high due to several factors, including restenosis in one third of the patients ${ }^{6}$. Recent studies have shown that in vascular endothelial cells, flow patterns are critical in the sense that they influence the initiation of atherosclerosis, in-stent restenosis, and bypass graft failure ${ }^{6}$. After balloon valvuloplasty, there is a relief in the pressure gradient across the aortic valve, however the hemodynamics do not resemble that of a normal valve, which could play an important role in the cause of restenosis. Valvular leaflet remodeling has been traced to endothelial cell dysfunction and denudation ${ }^{2}$, which is the primary suspect for the cause of restenosis in patients with balloon valvuloplasty. Valvular endothelial cells, like vascular 
endothelial cells, are known to remodel in response to hemodynamic environments by sensing the mechanical signals, and reorganizing the cytoskeletal filaments and the focal adhesion complexes, therefore altering gene expression ${ }^{2}$. By evaluating the changes in hemodynamics following balloon intervention, we can delineate the potential primary precursor which could be linked to underlying cause of rapid restenosis after balloon implantation.

\section{METHODS}

Isolation of porcine valvular endothelial cells (VECs)

Side specific porcine valvular endothelial cells were isolated as previously described in Gould, et.al $2010^{53}$. In brief, porcine heart valves were dissected and valvular endothelial cells from the ventricularis side and fibrosa side were dislodge using collagenase type II (Worthington Biochemicals, Lakewood, NJ). After isolation, cells were grown for 3 days for them to recover from the harsh process.

\section{Immunostaining VECs}

Isolated VECs were plated in pre-coated slides with collagen (BD Biosciences, Franklin Lakes, NJ). The following procedure was followed for subsequent staining: Isolated cells were cultured to $\sim 80 \%$ confluence and fixed with $4 \%$ formaldehyde. Fixed cells were permeabilized with $0.1 \%$ TritonX-100 for 5 min (this step was excluded for CD31 staining). Additional washing steps were performed three times with DPBS. Blocking nonspecific epitopes was facilitated by adding 3\% BSA in DPBS for 30 min. The primary antibodies used were rabbit polyclonal anti-smooth muscle actin (Abcan, Cambridge, MA) and goat polyclonal anti-CD31 (Abcan, Cambridge, MA). An overnight incubation 
at $4^{\circ}$ was done. Samples were later washed and the second antibody was added for 1 hours at room temperature. Fixed cells were later viewed under a fluorescent microscope (Olympus BX51, Center Valley, PA).

\section{Computational Fluid Dynamics}

In order to extract the shear stress waveforms, we conducted a CDF (Ansys Canonsburg, PA) simulation depicting the aortic structure from the normal patient and the patient who underwent balloon valvuloplasty. The geometry consisted of a $3 \mathrm{D}(\mathrm{x}, \mathrm{y}$, and $\mathrm{z}$ dimensions) structured mesh with 1.5million nodes. However analysis will be done along the $2 \mathrm{D}$ plane from which the geometry was built because the cross-section of the valve and artery geometry was not available from medical images. The measurements for each patient were obtained from JDCH through a sonogram (Figure 12, Figure 13). The velocity profile was fed to the inlet and the pressure profile was inputted to the output (Figure 14, Figure 15, Figure 16, and Figure 17). A transient simulation was used, placing the convergence criteria to $1 \times 10^{-6}$ for momentum and continuity, with time steps

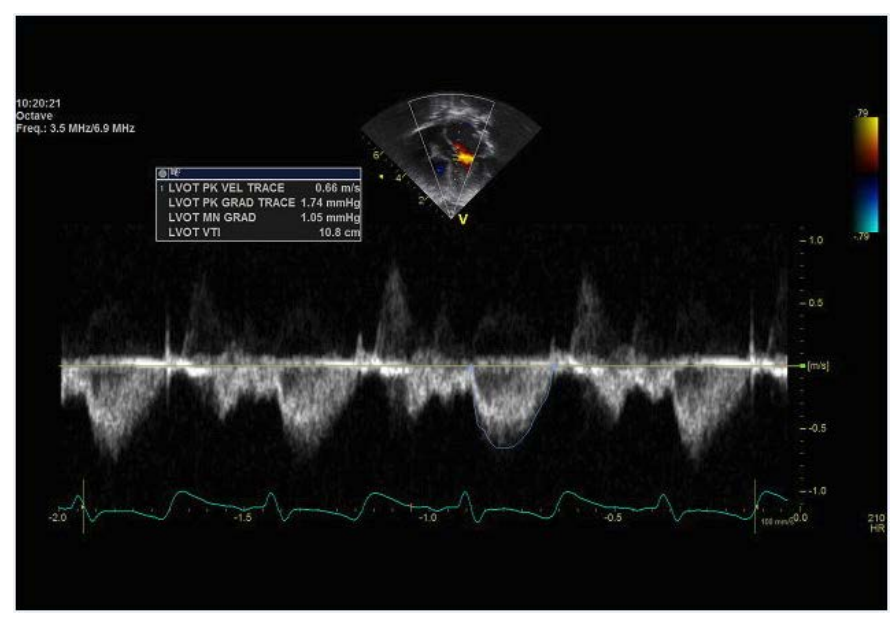

Figure 12. Echocardiography flow profiles from normal patient obtained from JDCH. 
of $0.1 \mathrm{~s}$. Blood properties were used in order to run the model.

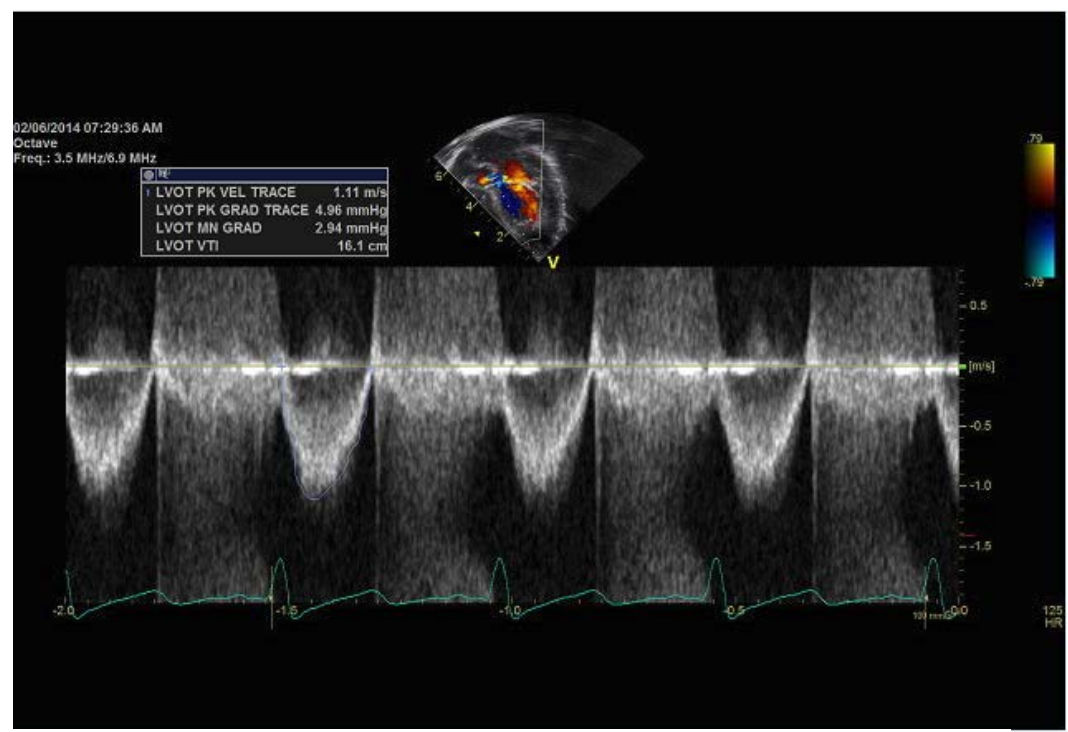

Figure 14. Echocardiography flow profiles from patient after balloon valvuloplasty obtained from JDCH

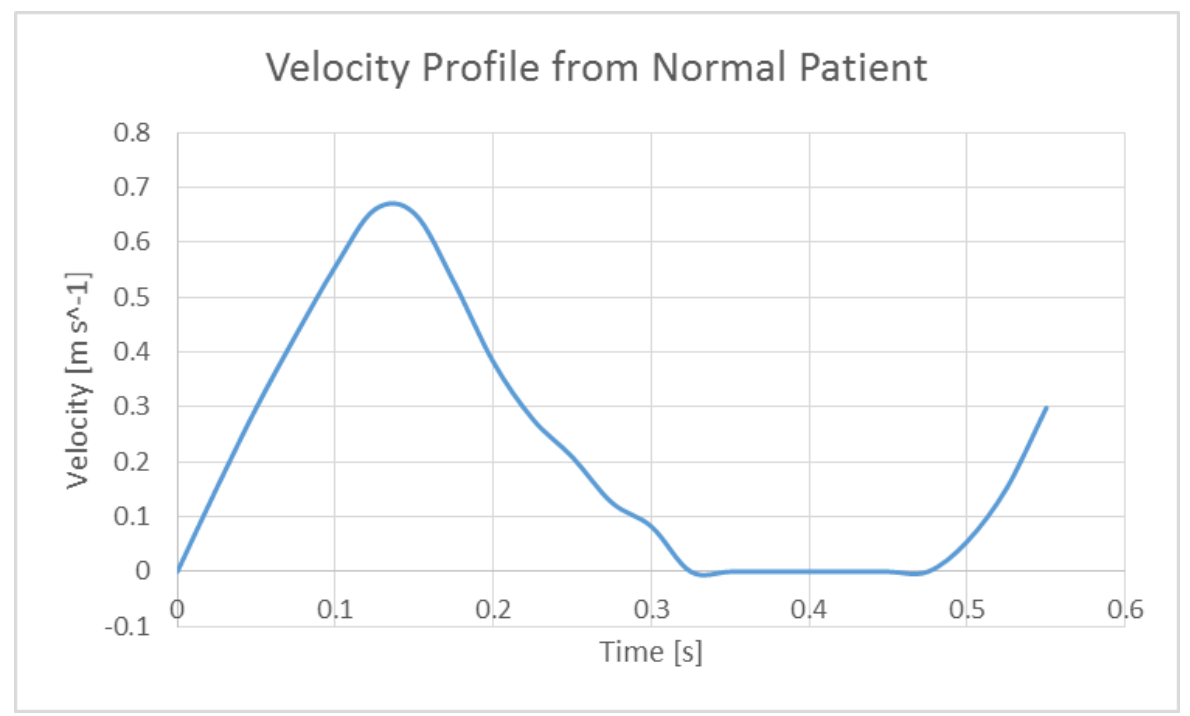

Figure 13. Velocity profile from a normal fed to the inlet in the simulation (Ansys CFD). 


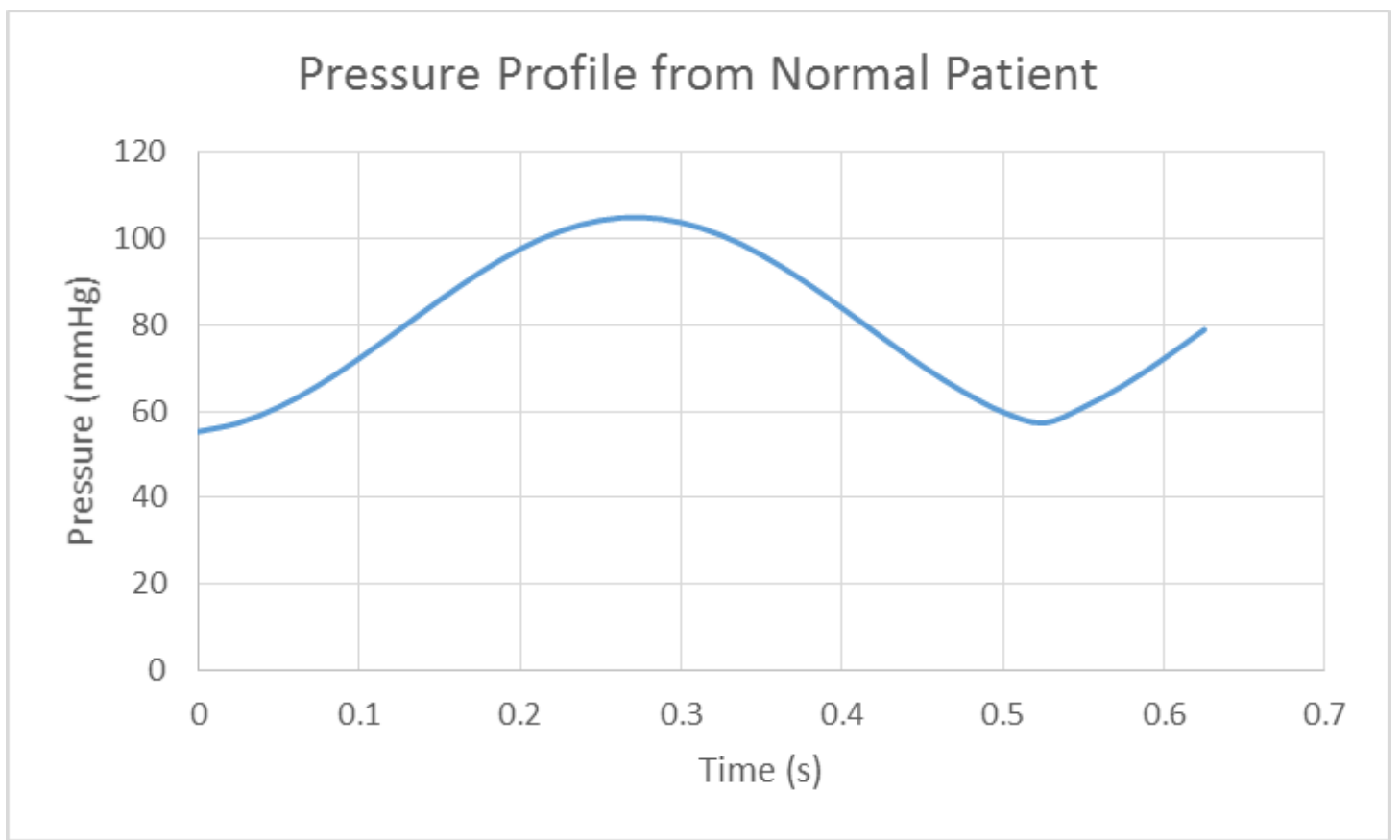

Figure 16. Velocity profile from a patient after balloon valvuloplasty fed to the inlet in the simulation (Ansys CFD)

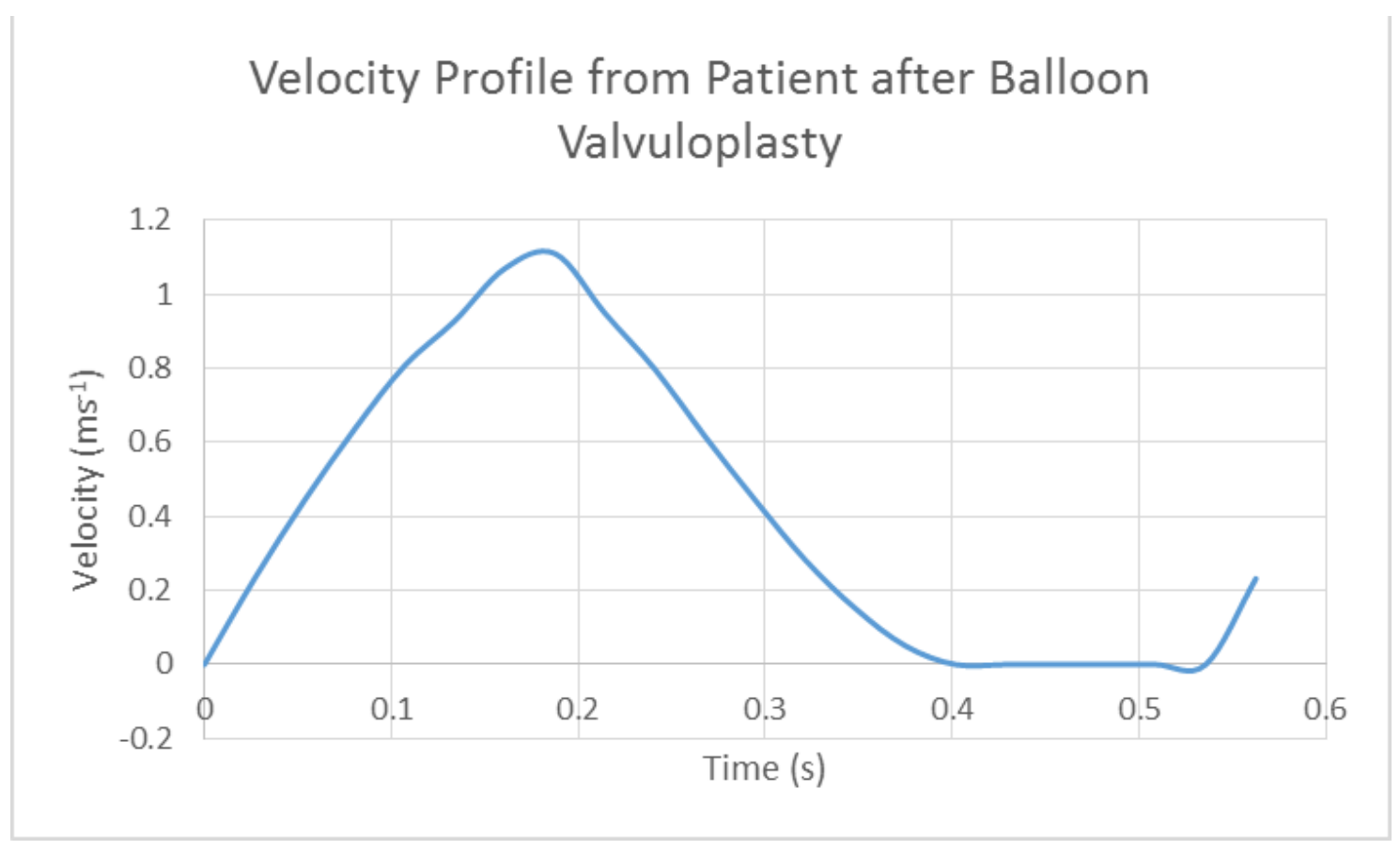

Figure 15. Pressure profile from a normal patient fed to the outlet in the simulation (Ansys CFD). 


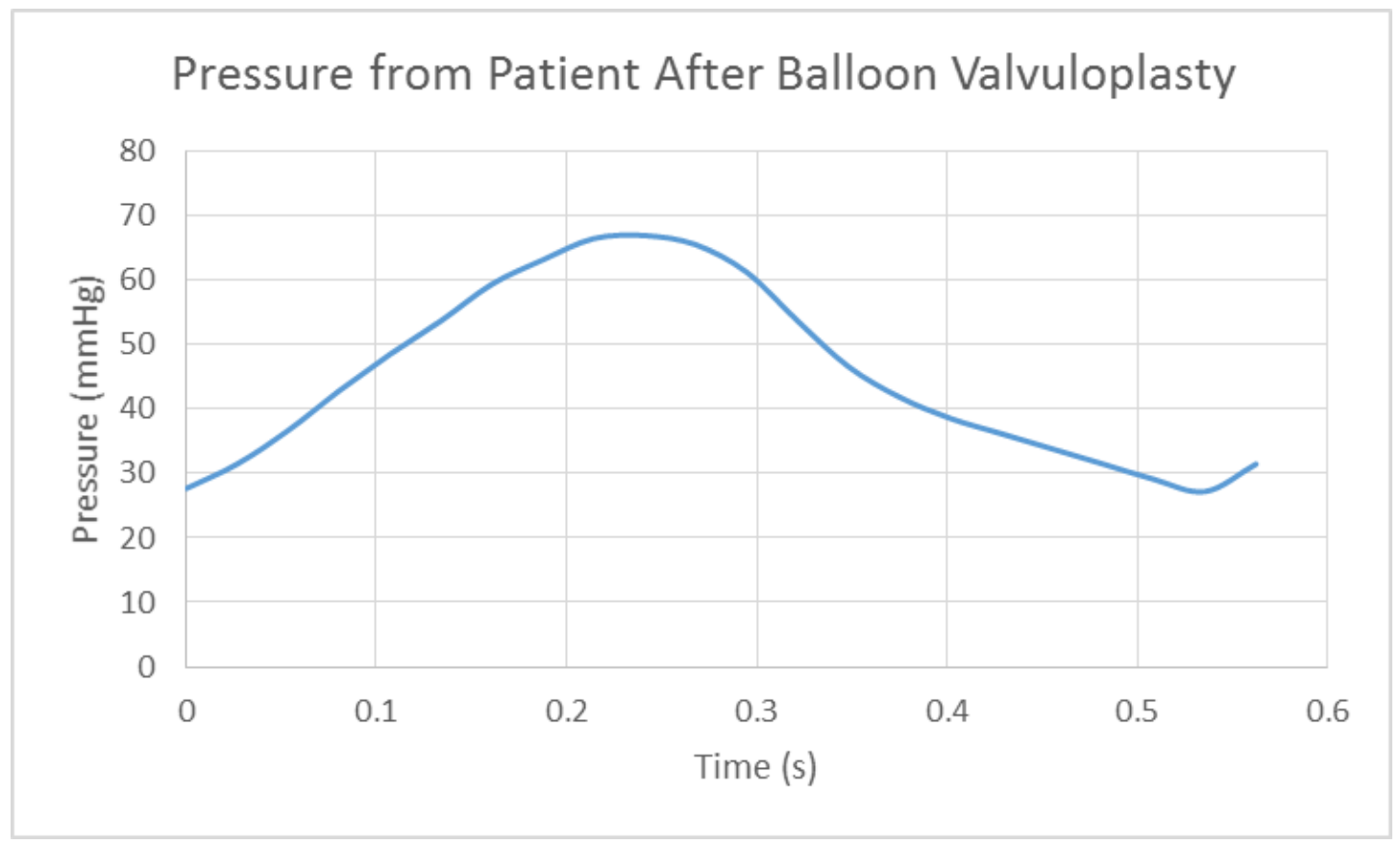

Figure 17. Pressure profile from a patient after balloon valvuloplasty fed to the outlet in the simulation (Ansys CFD).

\section{RESULTS}

\section{Model Validation}

In order to validate our model, the transvalvular pressure gradient from our model was compared to the transvalvular pressure from the clinical data. The inlet pressure waveform was also measured and compared the clinical data provided by the hospital. For the post-balloon model, the pressure gradient calculated by our model was 26.06mmHg, whereas the clinical was 26.00mmHg, giving a $0.23 \%$ error (Figure. 18). The inlet waveform calculated by the model is seen to resemble that of the clinical data (Figure. 19). For the normal heart valve, the transvalvular pressure calculated by the model was $8.20 \mathrm{mmHg}$, while the clinical calculate measurement was $6.50 \mathrm{mmHg}$, estimating a $25.15 \%$ error (Figure.20). The error observed is negated by the fact that the 
pressure drops are relatively small. Also, due to the fact that the pressure was not measured directly using a catheter, clinical measurement may not be accurate, calculating a high error. The calculated inlet pressure was $111.75 \mathrm{mmHg}$, as compared to the estimated value observed in clinical setting which was 120mmHg (Figure 21).

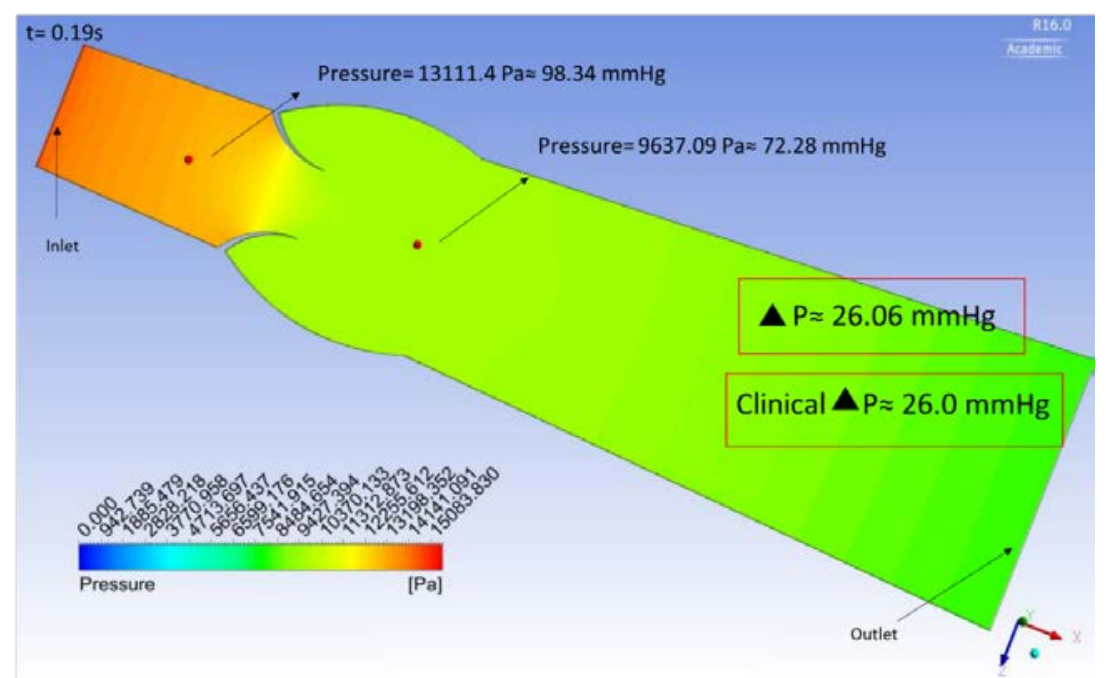

Figure 18. Transvavlular pressure gradient validation on the post-balloon valvuloplasty model.

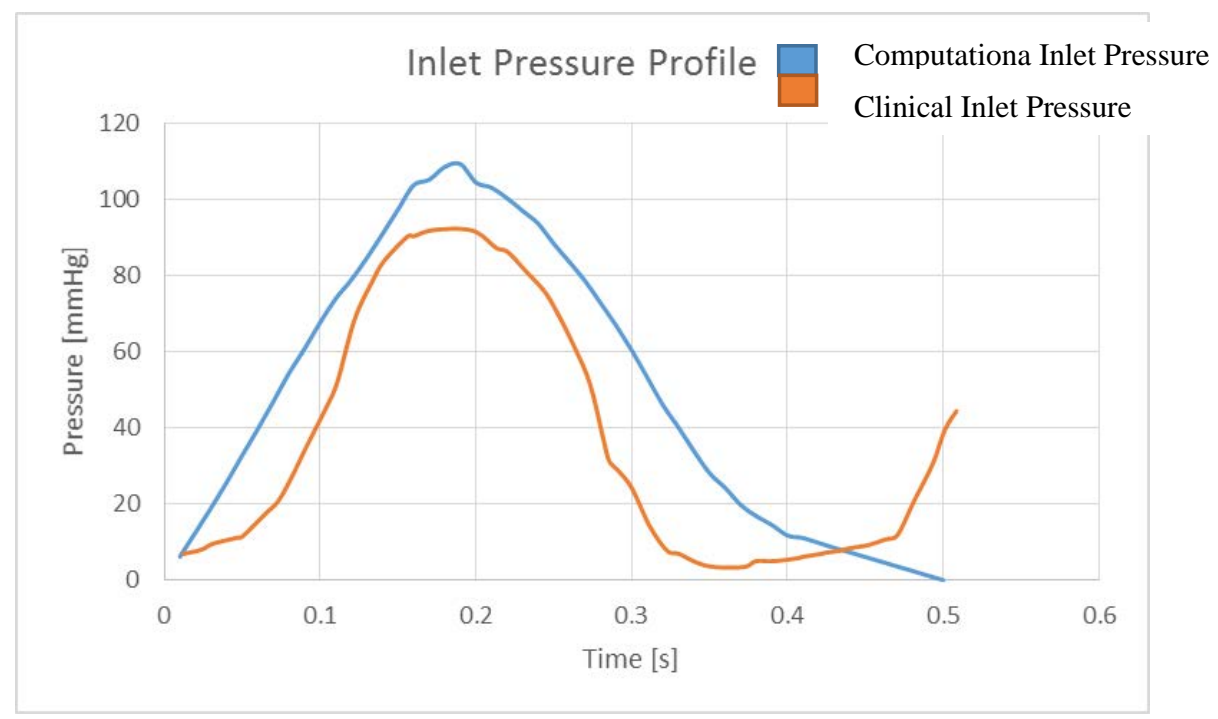

Figure 19. Inlet pressure waveform validation from treated heart valve. 
$t=0.14 \mathrm{~s}$

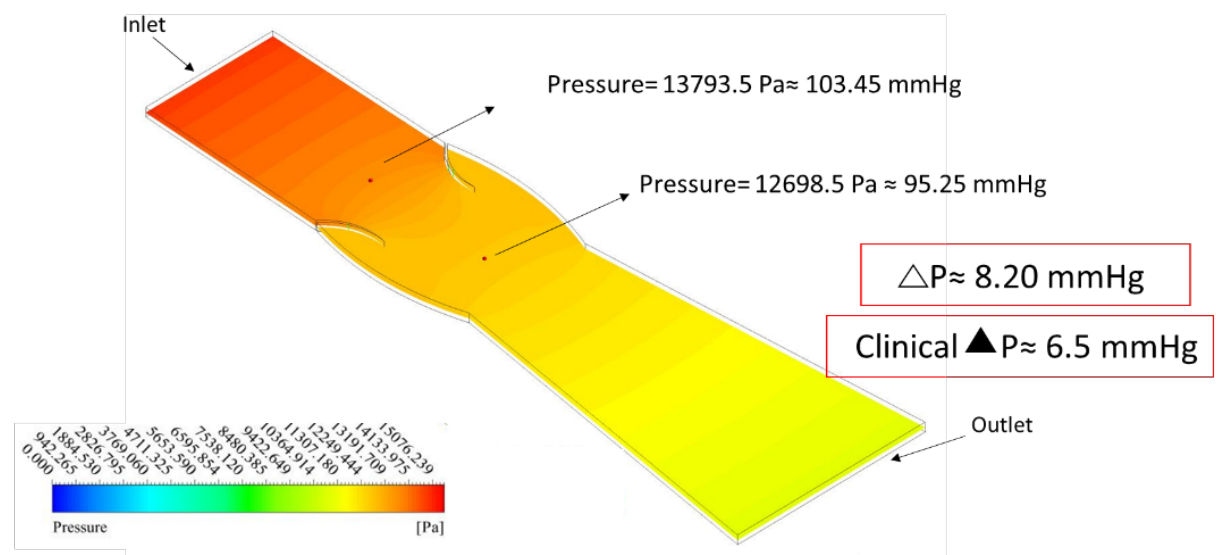

Figure 20. Transvalvular pressure gradient validation on the normal heart valve model.

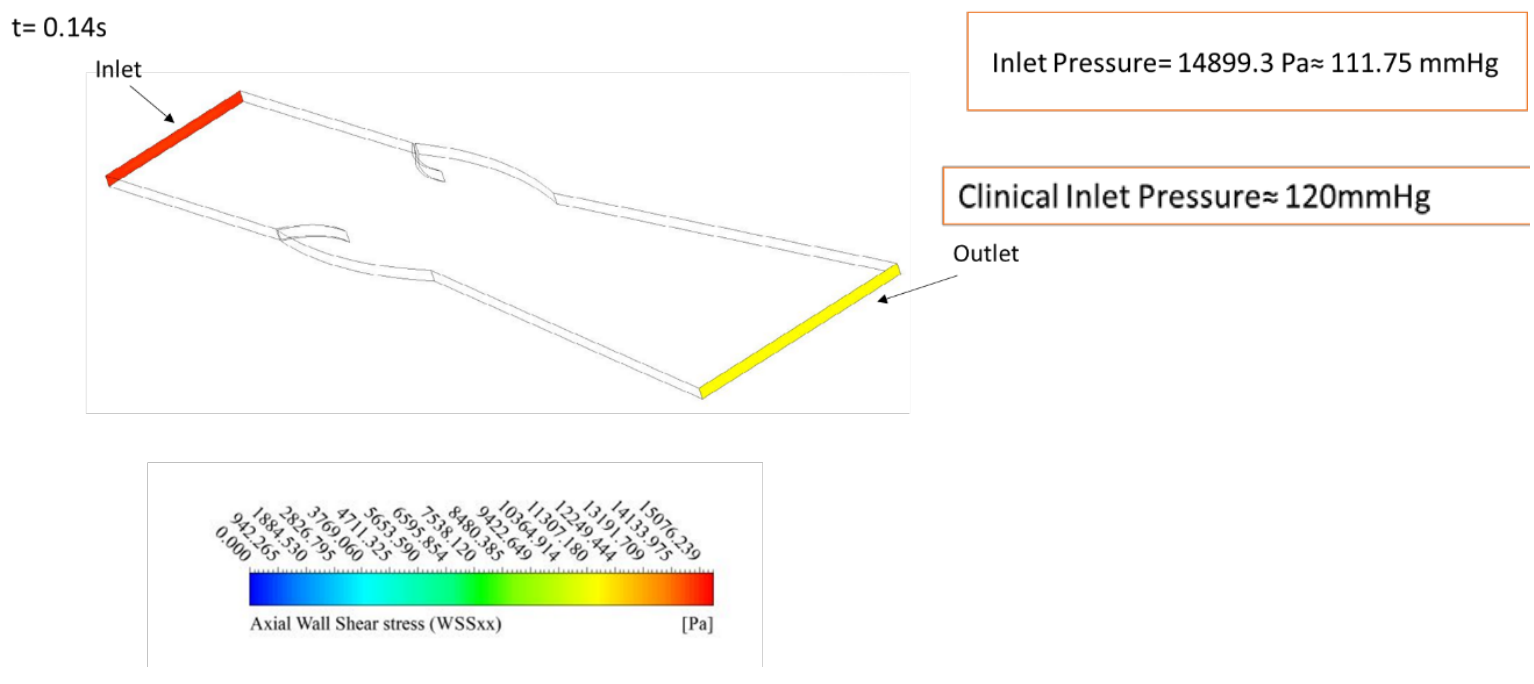

Figure 21 Inlet pressure validation from a healthy heart valve. 


\section{Immunostaining of VECs}

VECs were stained with CD31 to check for the presence of endothelial cells and $\alpha$-SMA to check for interstitial cells. Hoascht was used to stain the nucleus. We observe positive staining for CD31 (Figure 18), whereas we do not observe positive staining for $\alpha$-SMA suggesting successful isolation of valvular endothelial cells.

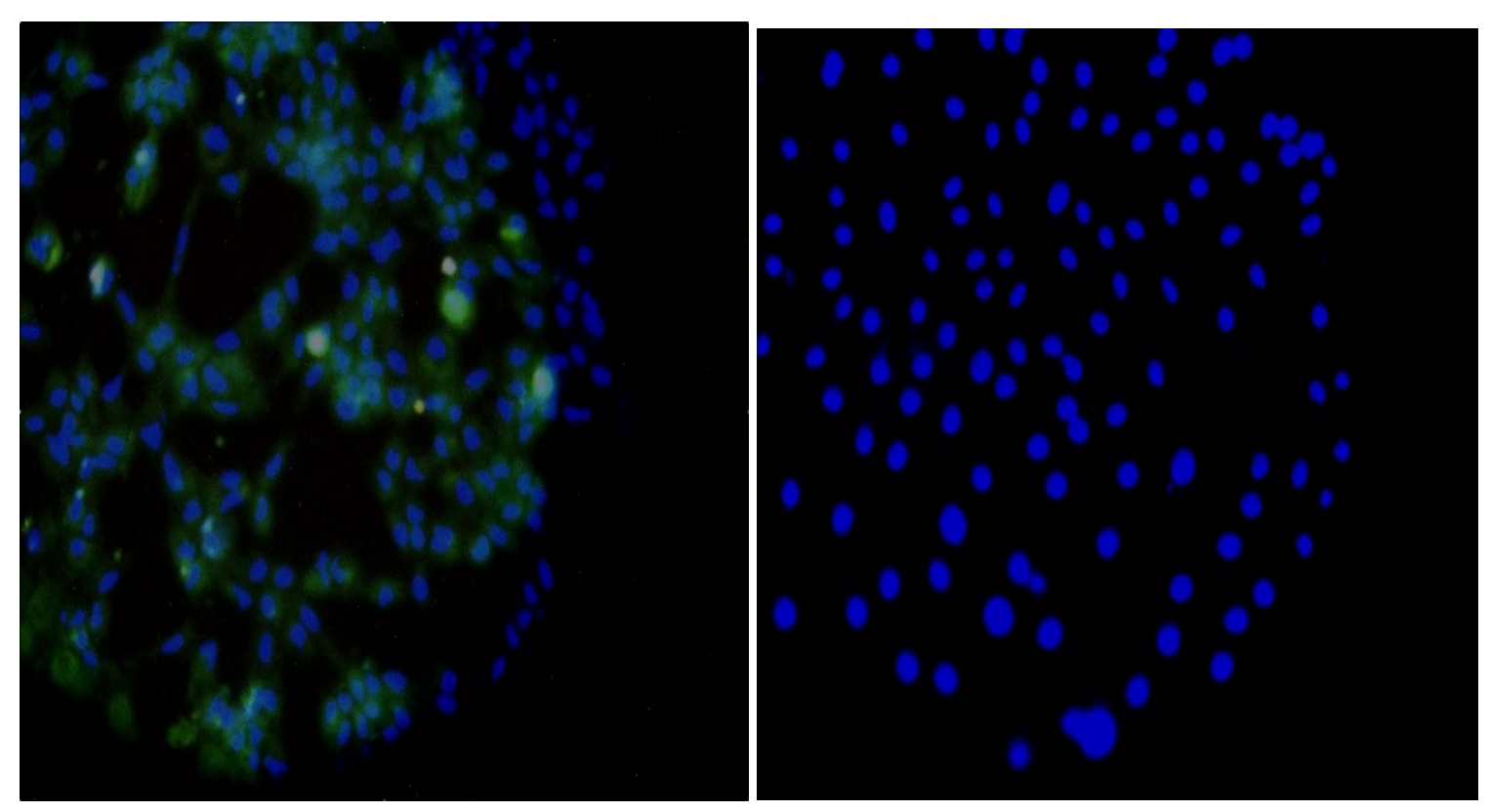

Figure 22. Isolated VECs stained positive for CD31 (Left). VECs stained negative for $\alpha$ SMA (Right). 
Time-Averaged Wall Shear stress (TAWSS)

There is a clear difference in the TAWSS (axial) between the normal patient and the patient who underwent balloon valvuloplasty on the fibrosa side. We observed peak shear stresses of $\sim 2.2 \mathrm{~Pa}$ on the leaflets of the normal patient (Figure 23). However, on the patient who underwent the treatment, we observed a peak wall shear stress of $\sim 3.2 \mathrm{~Pa}$ (Figure 24). Furthermore we observe a difference in the waveform between both patients.

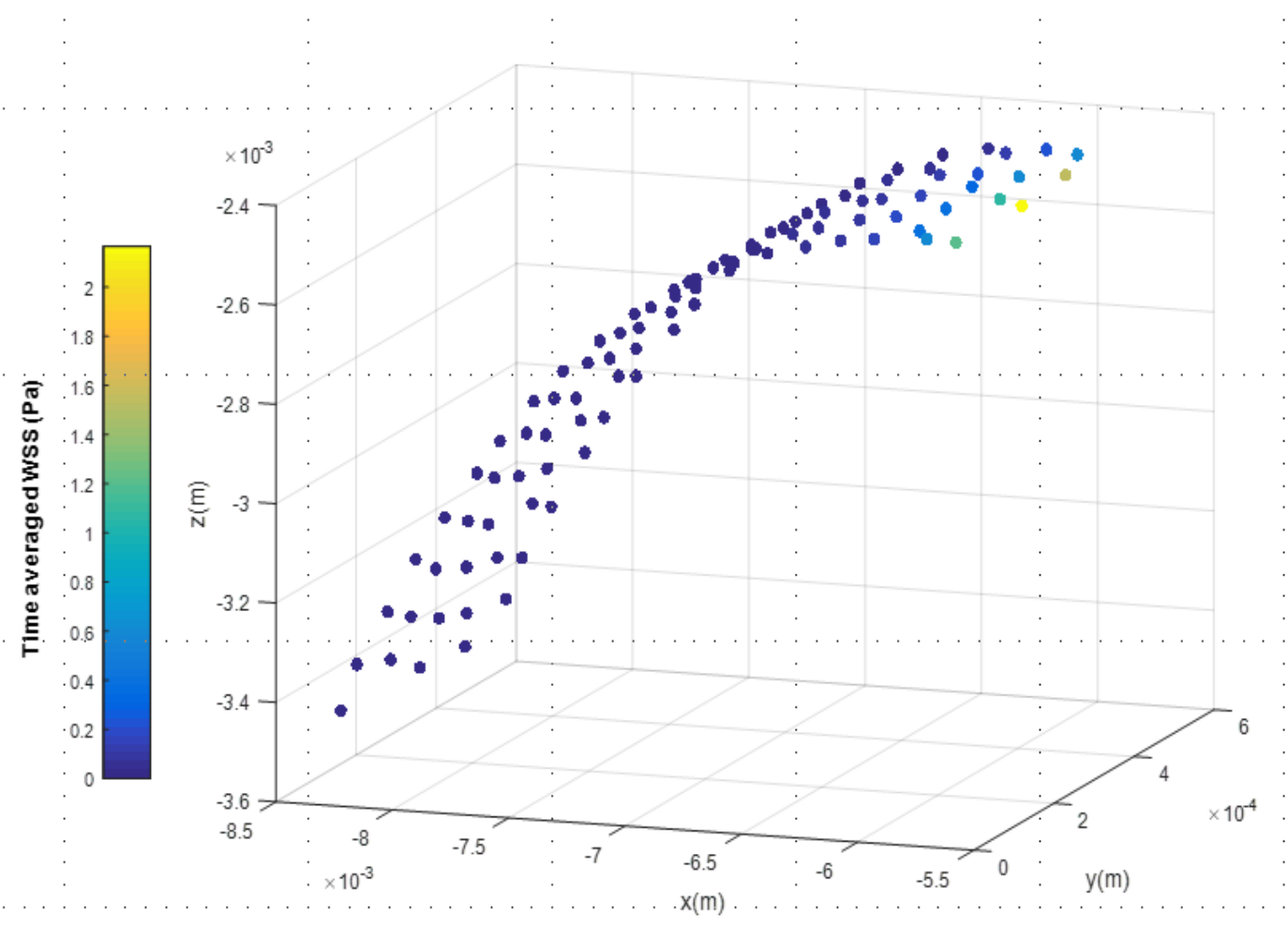

Figure 23. Time average wall shear stress on a normal patient. 


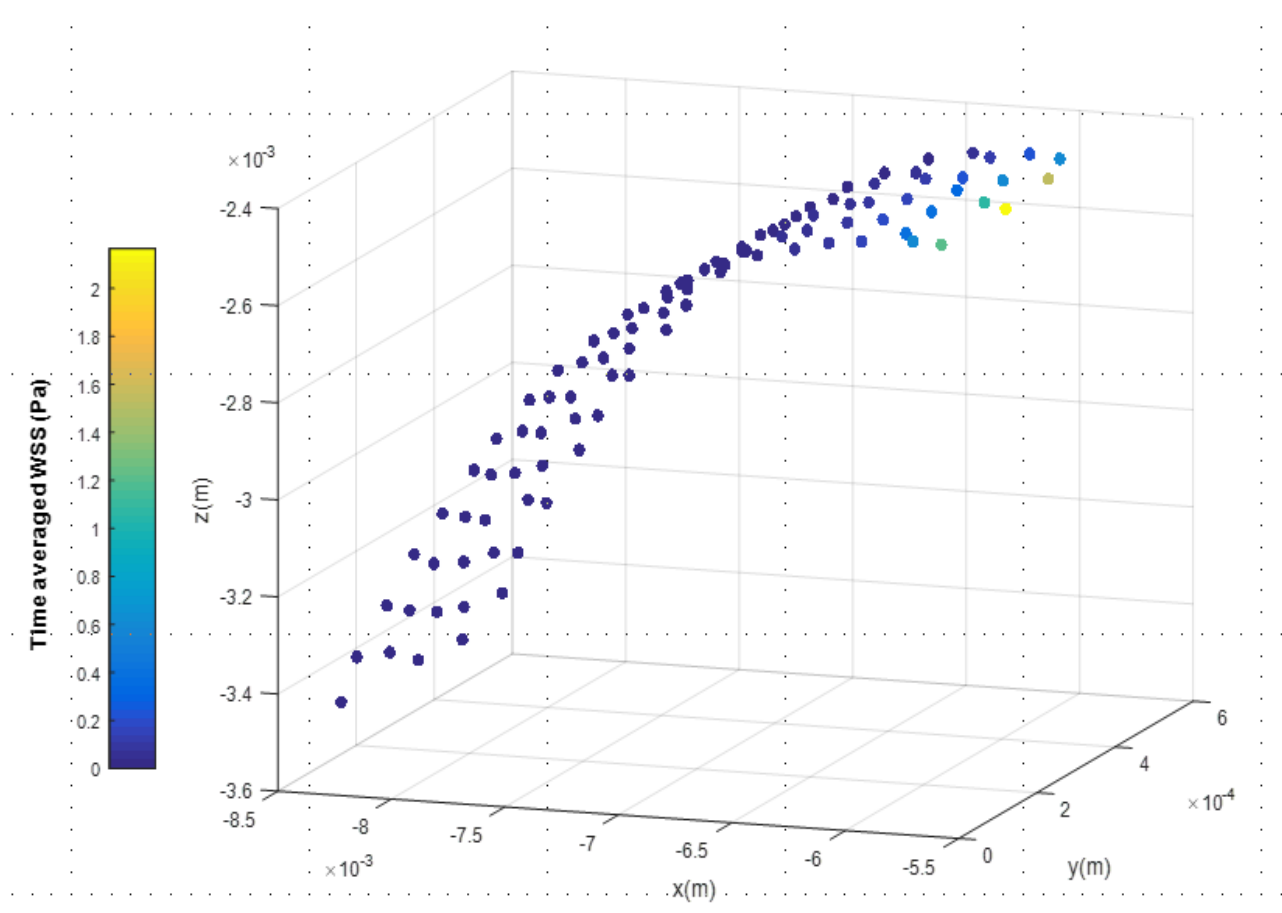

Figure 24. Time average wall shear stress on patient after treatment

\section{Spatial-Averaged Wall Shear Stress}

The axial wall shear stress was averaged spatially throughout the heart valve for each time point. We observe a difference in the waveforms from the normal patient and the patient after the treatment on the fibrosa side. Moreover the shear spatially-averaged wall shear stress from the normal patient has a peak value of $\sim 0.165$ Pa (Figure 25), while after the treatment the peak value is observed to be $\sim 0.45 \mathrm{~Pa}$ (Figure 26). 


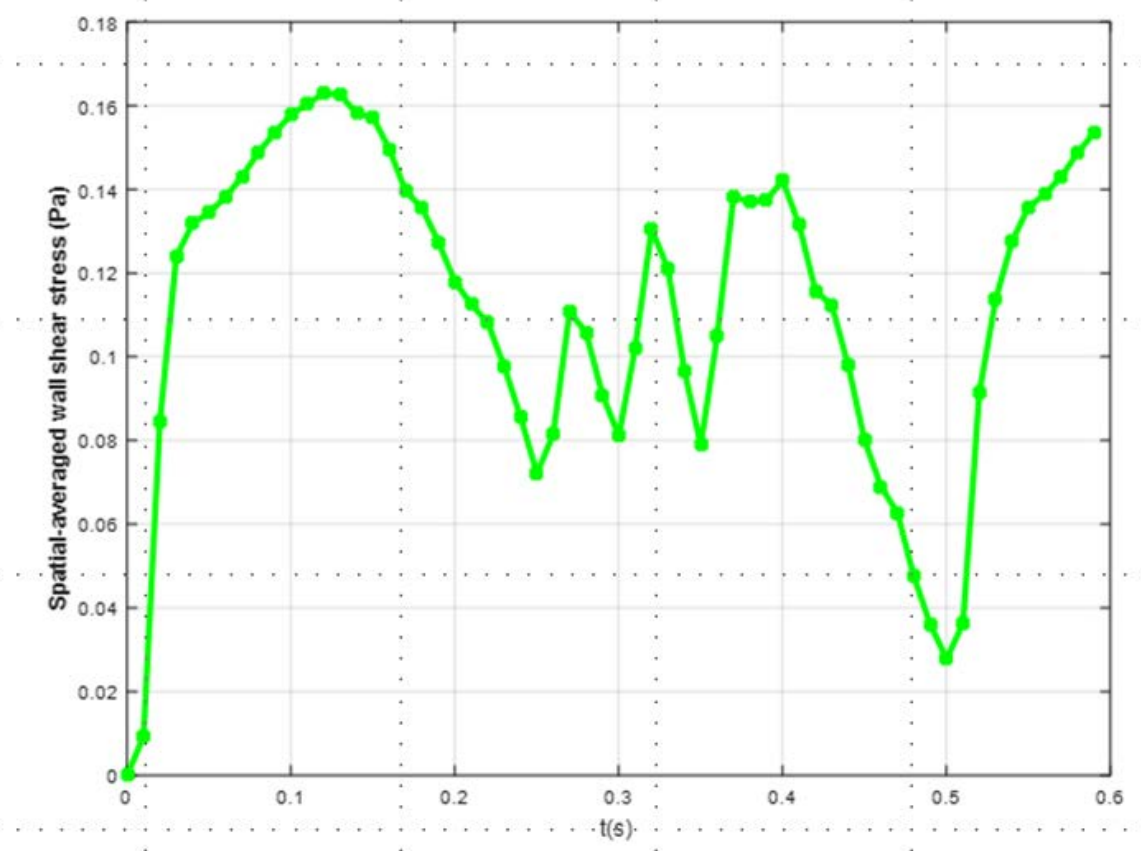

Figure 25. Spatially-averaged wall shear stress from the normal patient

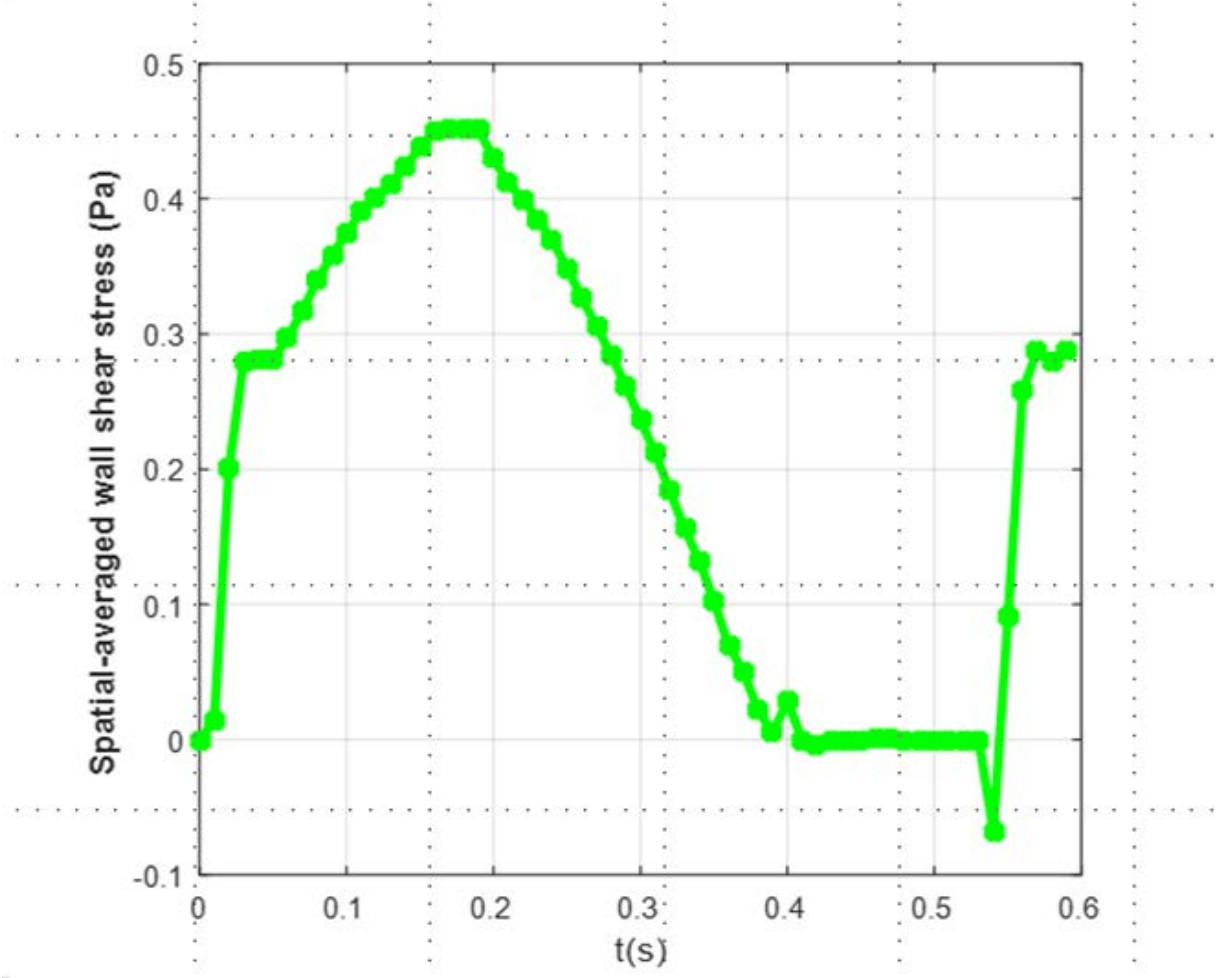

Figure 26. Spatially-averaged wall shear stress after balloon valvuloplasty. 


\section{Oscillatory Shear Index (OSI)}

OSI, is a measurement which quantifies the change in direction and magnitude of the wall shear stress (WSS), and it is calculated with the following formula:

$$
O S I=\frac{1}{2}\left(1-\frac{\left|\int_{0}^{T} \tau d t\right|}{\int_{0}^{T}|\tau| d t}\right)
$$

A Matlab code was created in order to measure the OSI throughout the valve. Side specific OSI was measure, fibrosa and ventricularis. We observe higher OSI in the fibrosa side compared to the ventricularis (Figure 27, Figure 28, Figure 29, and Figure 30). Comparing a healthy heart valve and a valve that underwent treatment, we also observe a difference in the OSI. There is higher OSI in the fibrosa side of the treated heart valve (Figure 27, Figure 29).

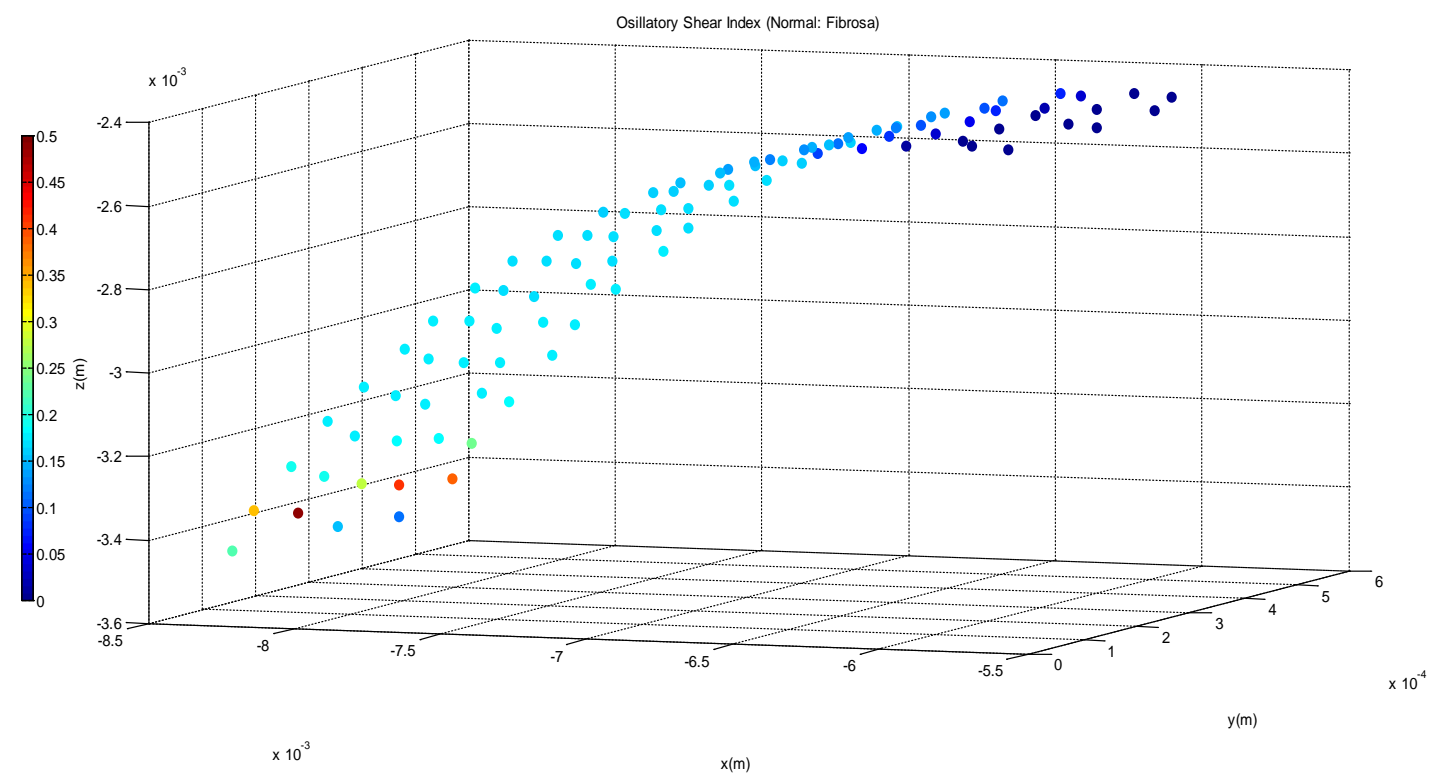

Figure 27. OSI fibrosa side of the healthy heart valve 


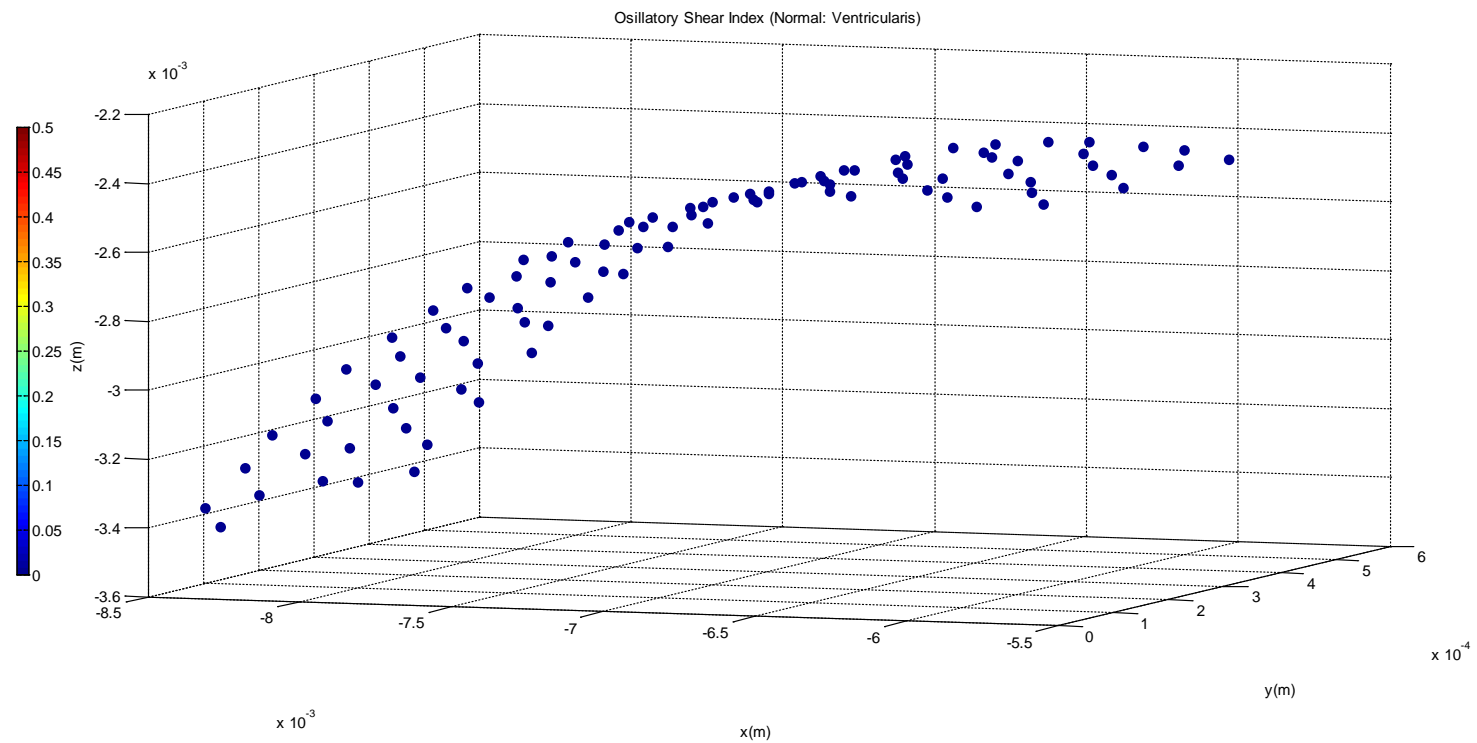

Figure 28.OSI ventricularis side of the healthy heart valve.

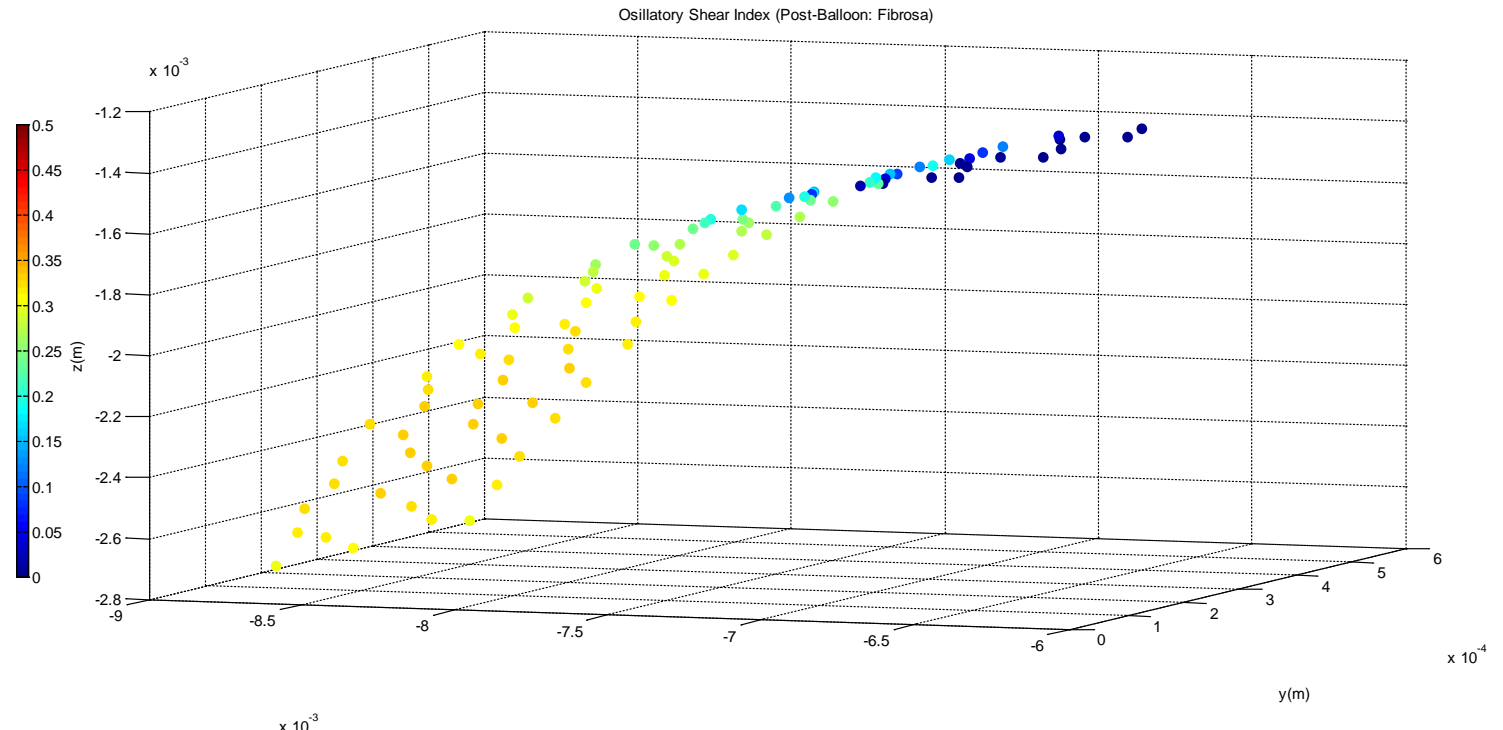

Figure 29. OSI fibrosa side of a heart valve that underwent treatment. 


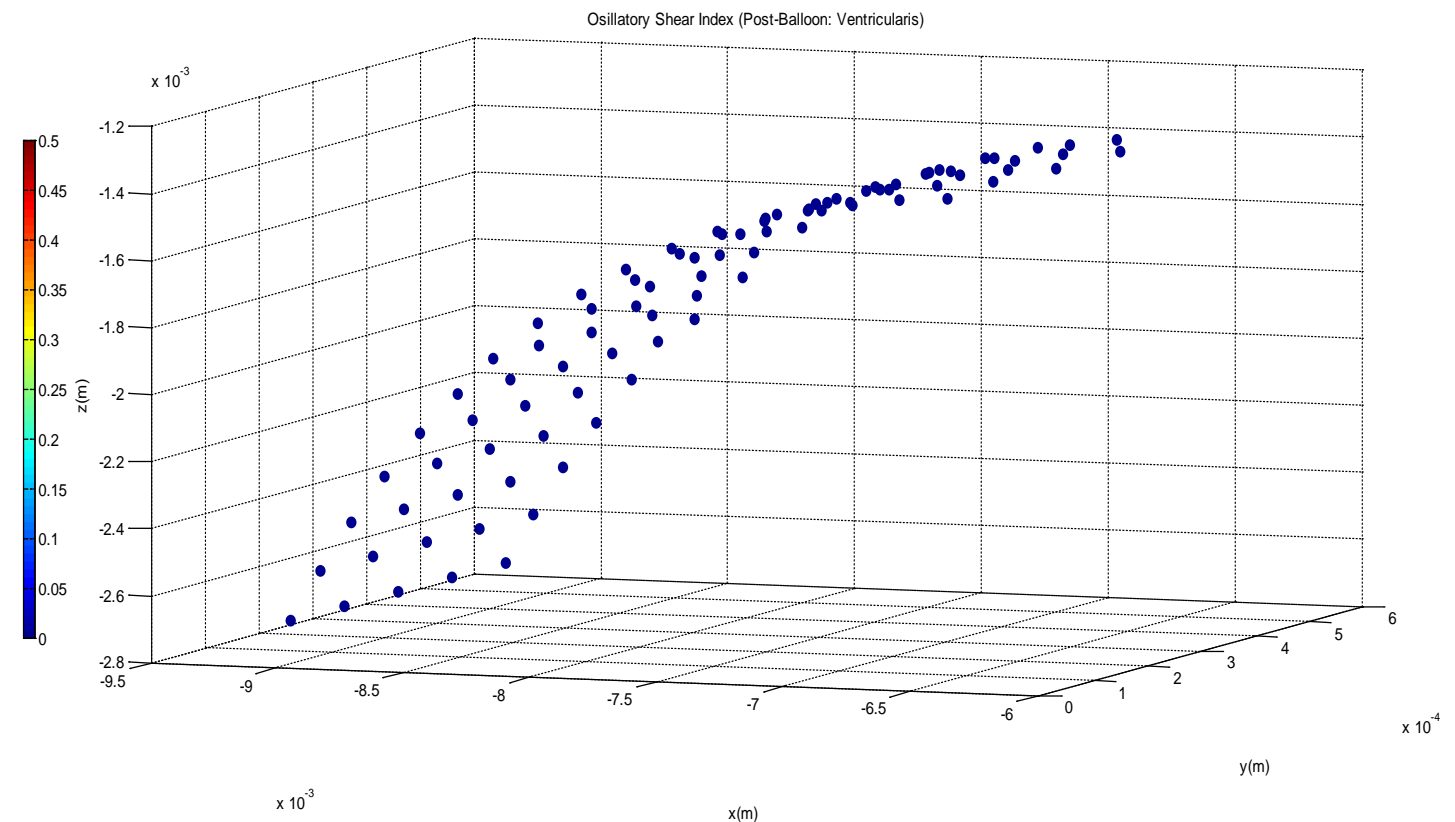

Figure 30. OSI ventricularis side of the heart valve that underwent treatment.

\section{DISCUSSION}

Aortic valve stenosis (AVS) was considered to be caused by deterioration of the heart valve which resulted in the formation of calcium deposits. However, recent studies have shown that AVS can be developed as part of a complex series of processes similar to atherosclerosis. As in atherosclerosis, the damaging of the endothelial layer due to an increase in mechanical stresses, is thought to be the initial event for developing AVS. Balloon aortic valvuloplasty, a treatment usually done on teenagers and children with aortic valve stenosis, consists of the widening of the valve using a balloon catheter. The balloon is inflated in between the valve in order to increase the effective orifice area and improve the blood flow. This less invasive approach for aortic stenosis treatment, allows the pressure gradient across the heart valve to decrease ( $\sim 60 \%)$, however restenosis is 
observed soon after balloon intervention. Furthermore, flow profiles revealed by echocardiograms of a healthy heart valve (Figure 12) and a heart valve after treated using balloon valvuloplasty (Figure 13) show a difference in the velocity profiles. The peak velocity calculated in the heart valve that underwent treatment was $1.11 \mathrm{~m} / \mathrm{s}$, while the peak velocity observed in the healthy heart valve was $0.66 \mathrm{~m} / \mathrm{s}$. Even though this treatment reduces the stenosis, this difference in the hemodynamics can inherently affect the valvular endothelial function in a negative manner. Appropriate hemodynamics is important for the function of the heart valve, however changes in velocities and pressures can have consequences in the microscopic scales. ${ }^{54}$ In atherosclerosis, recent studies have shown that the vascular endothelium is critical in the response of hemodynamic stimuli, and that atherosclerosis and endothelial inflammation occurs at the areas of disturbed flow ${ }^{55}$. Furthermore, high shear stress gradients have also been observed to alter endothelial cell function by altering growth factor and cytokine production, as well as altering the permeability of macromolecules and lipoproteins ${ }^{56}$. Similar to vascular endothelial cells, valvular endothelial cells (VECs) dysfunction is coupled with disturbed flow and leaflet degeneration and is also characterized by the expression of proinflammatory receptors ${ }^{57}$.

Blood flow-induced shear stress is an important mechanical stimuli that is found in the surface of the leaflets and it is important for VECs function. VECs have been shown to respond to shear stress, as they change morphologically and genetically when they are exposed to different shear stress conditions ${ }^{58}$. Shear stress profiles present in the fibrosa differ from that in the ventricularis side as they are exposed to different flow profiles. 
The ventricularis side, undergoes high shear stress values, and unidirectional flow, while the firbosa side experiences low shear stress values but oscillatory shear stress (OSS). Shear tress values in a normal heart valve from the fibrosa go up to 0.18 Pa (Figure 25) and in the ventricularis values go up to $\sim 28 \mathrm{~Pa}$. Valvular pathology seems to occur preferentially on the fribosa side, suggesting that oscillations observed in the firbosa side may contribute to the calcification of the heart valves. The vortices present in the firbosa side help the heart valve to close more efficiently at end systole. In our model we can observe such oscillations, however we can see a higher magnitude of oscillations in the treated heart valve. In order to quantify such oscillations we calculated the OSI from both sides, fibrosa and ventricularis. The OSI in the ventricularis is negligible as the OSI $\approx 0$ (Figure 28, Figure 30), however in the fibrosa side we see a higher OSI value. An even higher OSI distribution is observed in the heart valve which underwent balloon aortic valvuloplasty treatment (Figure 27, Figure 29). This finding suggests aberrant fluid oscillations along the arterial surface of the aortic valve that potentially may exceed physiologically-healthy states. As a consequence, we interpret abnormal VEC signaling and tissue factor activity may be provoked, leading to restenosed states. Confirmation of this hypothesis is a focus of current efforts in our laboratory, wherein arterial-side aortic VECs will be exposed to the aberrant levels of fluid-induced oscillations that were identified here. . Studies have shown endothelial phenotypes differ on opposite sides of the aortic valve. ${ }^{58}$ The fibrosa side, which is more prone to lesion formation, has shown to express multiple inhibitor of cardiovascular calcification in a lower degree than the ventricularis side ${ }^{58}$. Therefore the increase in oscillations seen in the treated heart valve, 
may cause the valve to restenosis in a more rapid manner as the fibrosa side is more vulnerable.

As we could observe in our model, there is a distinct difference in the hemodynamics of a healthy heart valve and a heart valve that underwent balloon valvuloplasty. Changes in hemodynamics have been linked to endothelial dysfunction, and therefore expression of certain markers that may play a role in calcification. Further in vitro studies need to be conducted in order to observe the response of the VECs to these altered profiles, such as shear stress. 


\section{CHAPTER V: FURTHER STUDIES}

As we have demonstrated, there are structural changes happening in BMSCs when exposed to OSS that may lead to the differentiation towards a valvular phenotype. We have previously shown the expression of valvular endothelial cell markers in BMSCs after being dynamically cultured using flex and OSS. We would like to confirm the correlation between the cytoskeletal changes observed to the differentiation and gene expression of BMSCs. Gene expression will be tested after BMSCs undergo OSS and SS in order to link it to the cytoskeletal changes. We clearly have shown the difference in averaged wall shear stress between the normal heart valve and one that has undergone balloon valvuloplasty. This change in hemodynamics can potentially damage the endothelial layer, which may lead to early calcification observed in patients that have been treated with balloon valvuloplasty. Here we have only shown results from the fibrosa side, however we would like to see the response of VECs in the ventricularis side as they are exposed to a higher shear stress. Changes in actin filaments and focal adhesions would be assessed as they have been shown to alter after being exposed to OSS and SS. 


\section{LIST OF REFERENCES}

1. Engelmayr GC,Jr, Rabkin E, Sutherland FW, Schoen FJ, Mayer JE,Jr, Sacks MS. The independent role of cyclic flexure in the early in vitro development of an engineered heart valve tissue. Biomaterials. 2005;26(2):175-187.

2. Butcher JT, Penrod AM, Garcia AJ, Nerem RM. Unique morphology and focal adhesion development of valvular endothelial cells in static and fluid flow environments. Arterioscler Thromb Vasc Biol. 2004;24(8):1429-1434.

3. Butcher JT, Nerem RM. Valvular endothelial cells and the mechanoregulation of valvular pathology. Philos Trans R Soc Lond B Biol Sci. 2007;362(1484):1445-1457.

4. Botto LD, Correa A, Erickson JD. Racial and temporal variations in the prevalence of heart defects. Pediatrics. 2001;107(3):E32.

5. Center of Disease Control and Prevention. Heart disease

facts. http://www.cdc.gov/heartdisease/facts.htm. Updated 2015. Accessed 09/07, 2015.

6. Wang C, Baker BM, Chen CS, Schwartz MA. Endothelial cell sensing of flow direction. Arterioscler Thromb Vasc Biol. 2013;33(9):2130-2136.

7. Emani S, Mayer JE,Jr, Emani SM. Gene regulation of extracellular matrix remodeling in human bone marrow stem cell-seeded tissue-engineered grafts. Tissue Eng Part A. 2011;17(19-20):2379-2388.

8. Sutherland FW, Perry TE, Yu Y, et al. From stem cells to viable autologous semilunar heart valve. Circulation. 2005;111(21):2783-2791.

9. Park JS, Huang NF, Kurpinski KT, Patel S, Hsu S, Li S. Mechanobiology of mesenchymal stem cells and their use in cardiovascular repair. Front Biosci. 2007;12:5098-5116.

10. Sacks MS, David Merryman W, Schmidt DE. On the biomechanics of heart valve function. J Biomech. 2009;42(12):1804-1824.

11. Engelmayr GC,Jr, Sales VL, Mayer JE,Jr, Sacks MS. Cyclic flexure and laminar flow synergistically accelerate mesenchymal stem cell-mediated engineered tissue formation: Implications for engineered heart valve tissues. Biomaterials. 2006;27(36):6083-6095.

12. Latif N, Sarathchandra P, Taylor PM, Antoniw J, Yacoub MH. Localization and pattern of expression of extracellular matrix components in human heart valves. $J$ Heart Valve Dis. 2005;14(2):218-227. 
13. Mahler GJ, Frendl CM, Cao Q, Butcher JT. Effects of shear stress pattern and magnitude on mesenchymal transformation and invasion of aortic valve endothelial cells. Biotechnol Bioeng. 2014;111(11):2326-2337.

14. Hasan A, Ragaert K, Swieszkowski W, et al. Biomechanical properties of native and tissue engineered heart valve constructs. J Biomech. 2014;47(9):1949-1963.

15. Butcher JT, Mahler GJ, Hockaday LA. Aortic valve disease and treatment: The need for naturally engineered solutions. Adv Drug Deliv Rev. 2011;63(4-5):242-268.

16. Weston MW, LaBorde DV, Yoganathan AP. Estimation of the shear stress on the surface of an aortic valve leaflet. Ann Biomed Eng. 1999;27(4):572-579.

17. Butcher JT, Nerem RM. Valvular endothelial cells regulate the phenotype of interstitial cells in co-culture: Effects of steady shear stress. Tissue Eng. 2006;12(4):905915.

18. Imberti B, Seliktar D, Nerem RM, Remuzzi A. The response of endothelial cells to fluid shear stress using a co-culture model of the arterial wall. Endothelium. 2002;9(1):11-23.

19. Butcher JT, Tressel S, Johnson T, et al. Transcriptional profiles of valvular and vascular endothelial cells reveal phenotypic differences: Influence of shear stress. Arterioscler Thromb Vasc Biol. 2006;26(1):69-77.

20. Farivar RS, Cohn LH, Soltesz EG, Mihaljevic T, Rawn JD, Byrne JG. Transcriptional profiling and growth kinetics of endothelium reveals differences between cells derived from porcine aorta versus aortic valve. Eur J Cardiothorac Surg. 2003;24(4):527-534.

21. Balachandran K, Alford PW, Wylie-Sears J, et al. Cyclic strain induces dual-mode endothelial-mesenchymal transformation of the cardiac valve. Proc Natl Acad Sci U S A. 2011;108(50):19943-19948.

22. Nakajima Y, Mironov V, Yamagishi T, Nakamura H, Markwald RR. Expression of smooth muscle alpha-actin in mesenchymal cells during formation of avian endocardial cushion tissue: A role for transforming growth factor beta3. Dev Dyn. 1997;209(3):296309.

23. Armstrong EJ, Bischoff J. Heart valve development: Endothelial cell signaling and differentiation. Circ Res. 2004;95(5):459-470.

24. Liu AC, Joag VR, Gotlieb AI. The emerging role of valve interstitial cell phenotypes in regulating heart valve pathobiology. Am J Pathol. 2007;171(5):1407-1418. 
25. Sacks MS, Yoganathan AP. Heart valve function: A biomechanical perspective. Philos Trans R Soc Lond B Biol Sci. 2007;362(1484):1369-1391.

26. Taylor PM, Batten P, Brand NJ, Thomas PS, Yacoub MH. The cardiac valve interstitial cell. Int J Biochem Cell Biol. 2003;35(2):113-118.

27. Otto CM. Clinical practice. evaluation and management of chronic mitral regurgitation. $N$ Engl J Med. 2001;345(10):740-746.

28. Thubrikar M, Piepgrass WC, Bosher LP, Nolan SP. The elastic modulus of canine aortic valve leaflets in vivo and in vitro. Circ Res. 1980;47(5):792-800.

29. Thubrikar MJ, Aouad J, Nolan SP. Comparison of the in vivo and in vitro mechanical properties of aortic valve leaflets. J Thorac Cardiovasc Surg. 1986;92(1):29-36.

30. Smith DB, Sacks MS, Vorp DA, Thornton M. Surface geometric analysis of anatomic structures using biquintic finite element interpolation. Ann Biomed Eng. 2000;28(6):598611.

31. Sathyamurthy I, Alex S. Calcific aortic valve disease: Is it another face of atherosclerosis? Indian Heart J. 2015;67(5):503-506.

32. Pawade TA, Newby DE, Dweck MR. Calcification in aortic stenosis: The skeleton key. J Am Coll Cardiol. 2015;66(5):561-577.

33. Sucosky P, Balachandran K, Elhammali A, Jo H, Yoganathan AP. Altered shear stress stimulates upregulation of endothelial VCAM-1 and ICAM-1 in a BMP-4- and TGF-beta1-dependent pathway. Arterioscler Thromb Vasc Biol. 2009;29(2):254-260.

34. Yoganathan AP. Fluid mechanics of aortic stenosis. Eur Heart J. 1988;9 Suppl E:1317.

35. Hasan A, Ragaert K, Swieszkowski W, et al. Biomechanical properties of native and tissue engineered heart valve constructs. J Biomech. 2014;47(9):1949-1963.

36. Hoerstrup SP, Sodian R, Daebritz S, et al. Functional living trileaflet heart valves grown in vitro. Circulation. 2000;102(19 Suppl 3):III44-9.

37. Sutherland FW, Perry TE, Yu Y, et al. From stem cells to viable autologous semilunar heart valve. Circulation. 2005;111(21):2783-2791.

38. Sewell-Loftin MK, Chun YW, Khademhosseini A, Merryman WD. EMT-inducing biomaterials for heart valve engineering: Taking cues from developmental biology. $J$ Cardiovasc Transl Res. 2011;4(5):658-671. 
39. Ferencz C, Rubin JD, McCarter RJ, et al. Congenital heart disease: Prevalence at livebirth. the baltimore-washington infant study. Am J Epidemiol. 1985;121(1):31-36.

40. Centers for Disease Control and Prevention (CDC). Racial differences by gestational age in neonatal deaths attributable to congenital heart defects --- united states, 2003-2006. MMWR Morb Mortal Wkly Rep. 2010;59(37):1208-1211.

41. Ngozi CA, P. Syamasundar R. Balloon aortic valvuloplasty. Pediatrics \& Therapeutics. 2012;S5(004):200-209.

42. Bates E. Treatment options in severe aortic stenosis. Circulation. 2011;124:355-359.

43. Yim EK, Sheetz MP. Force-dependent cell signaling in stem cell differentiation. Stem Cell Res Ther. 2012;3(5):41.

44. Huang Y, Zheng L, Gong X, et al. Effect of cyclic strain on cardiomyogenic differentiation of rat bone marrow derived mesenchymal stem cells. PLoS One. 2012;7(4):e34960.

45. Adamo L, Garcia-Cardena G. Directed stem cell differentiation by fluid mechanical forces. Antioxid Redox Signal. 2011;15(5):1463-1473.

46. Osborn EA, Rabodzey A, Dewey CF,Jr, Hartwig JH. Endothelial actin cytoskeleton remodeling during mechanostimulation with fluid shear stress. Am J Physiol Cell Physiol. 2006;290(2):C444-52.

47. Ito K, Sakamoto N, Ohashi T, Sato M. Effects of frequency of pulsatile flow on morphology and integrin expression of vascular endothelial cells. Technol Health Care. 2007;15(2):91-101.

48. Jones TD, Naimipour H, Sun S, Cho M, Alapati SB. Mechanical changes in human dental pulp stem cells during early odontogenic differentiation. J Endod. 2015;41(1):5055.

49. Nava MM, Raimondi MT, Pietrabissa R. Controlling self-renewal and differentiation of stem cells via mechanical cues. J Biomed Biotechnol. 2012;2012:797410.

50. Rath S, Salinas M, Bhatacharjee S, Ramaswamy S. Marrow stem cell differentiation for valvulogenesis via oscillatory flow and nicotine agonists: Unusual suspects? J Long Term Eff Med Implants. 2015;25(1-2):147-160.

51. Salinas M, Ramaswamy S. Computational simulations predict a key role for oscillatory fluid shear stress in de novo valvular tissue formation. $J$ Biomech. 2014;47(14):3517-3523. 
52. Helledie T, Nurcombe V, Cool SM. A simple and reliable electroporation method for human bone marrow mesenchymal stem cells. Stem Cells Dev. 2008;17(4):837-848.

53. Gould RA, Butcher JT. Isolation of valvular endothelial cells. J Vis Exp. 2010;(46). pii: 2158. doi(46):10.3791/2158.

54. Gould ST, Srigunapalan S, Simmons CA, Anseth KS. Hemodynamic and cellular response feedback in calcific aortic valve disease. Circ Res. 2013;113(2):186-197.

55. Chappell DC, Varner SE, Nerem RM, Medford RM, Alexander RW. Oscillatory shear stress stimulates adhesion molecule expression in cultured human endothelium. Circ Res. 1998;82(5):532-539.

56. DePaola N, Gimbrone MA,Jr, Davies PF, Dewey CF,Jr. Vascular endothelium responds to fluid shear stress gradients. Arterioscler Thromb. 1992;12(11):1254-1257.

57. Ghaisas NK, Foley JB, O'Briain DS, Crean P, Kelleher D, Walsh M. Adhesion molecules in nonrheumatic aortic valve disease: Endothelial expression, serum levels and effects of valve replacement. J Am Coll Cardiol. 2000;36(7):2257-2262.

58. Butcher JT, Simmons CA, Warnock JN. Mechanobiology of the aortic heart valve. $J$ Heart Valve Dis. 2008;17(1):62-73. 